\title{
Die Genese der Leipziger Artikel von 1548/49 zwischen politischer Einflussnahme und lutherischer Bekenntnispflicht
}

\author{
von \\ FELIX ENGEL
}

Im Jahr 1550 verlieh der in Magdeburg ansässige Theologe Matthias Flacius Illyricus seiner Sorge über die schleichende Zerstörung der evangelischen Kirche als Garant für den ,wahren', also lutherischen Glauben Ausdruck: Offt vorwar/ wenn ich die jegenwertigen betriegerey/ so sie der waren Riligion stellen/ mit mir betrachte/ so mercke ich/ das sie einem keil/ gantz enlich ond gleich sein/ welcher am fördersten teil/ forne an der spitzen gantz dunne ond scharff ist/ das man nicht meinet/ wenn ebr gleich ins holtz geschlagen würde, das ehr es sebr auffreissen solte. Aber doch/ wiewol ehr foran gar dünne ist/ so macht ehr doch nichts deste weniger der folgenden dickeit einen zuganck/ ond zutrit/ also/ das/ wenn das erste teil ist eingegangen/ auch das ander wird leichtlich folgen/ biss zu letzt/ das boltz gantz und gar von einander gespalten wird. [...] Die erste ond förderste spitze des verfluchten/ onnd schedlichen Keils/ ist nur allein ein Korrock/ odder auch die veriagung etlicher bestendigen und fromen Prediger. Das ander teil/ so ein wenig dicker ist/ ist der Ausszug des Leiptzischen Interims. Das mittel/ ond ein wol dicke teil/ ist das Leiptzische Interim. Weiter das hinderste onnd dickste teil/ ist das Augspurgische Interim/ ond das gantze Babstumb. Vnd ist also dis gantze ongelück/ nur ein einiges instrument vnnd werckzeng des Teuffels/ damit die ware Gotfürchticheit/ ond die gantze Kirche zerstöret wird. ${ }^{1}$

Worauf wollte der streitbare Lutheraner mit dieser Keil-Metapher hinaus? Nach dem Tode des Reformators Martin Luther hatte sich Kaiser Karl V. dazu veranlasst gesehen, die Einheit der Kirche im Alten Reich zu erzwingen, da alle gütlichen Einigungsversuche zwischen Protestanten und Katholiken gescheitert waren. Zudem ermöglichte dem Kaiser die befriedete außenpolitische Situation, die Mitglieder des Schmalkaldischen Bundes mittels eines Waffenganges für seine Reunionsbestrebungen gefügig $\mathrm{zu}$ machen. Der Schmalkaldische Krieg von $1546 / 47^{2}$ ging für die Protestanten verloren, und die Machtverhältnisse wurden im

1 Matthias Flacius Illyricus, Ein Christliche vermanung M. Matthie Flacij Jllyrici zur bestendigkeit/ inn der waren reinen Religion Jhesu Christi/ [...], Magdeburg 1550 (VD 16: F 1300), fol. $\mathrm{D}^{\mathrm{r}}-\mathrm{D} \mathrm{ij}^{\mathrm{r}}$.

2 Vgl. beispielsweise Karlheinz Blaschke (Hg.), Moritz von Sachsen. Ein Fürst der Reformationszeit zwischen Territorium und Reich (Quellen und Forschungen zur sächsischen Geschichte 29), Stuttgart 2007; Heiko Jadatz, Der Schmalkaldische Krieg 
Reich und mit dem Wechsel der sächsischen Kurwürde insbesondere in Mitteldeutschland neu verteilt. Daraufhin ließ der Kaiser auf dem Reichstag zu Augsburg 1547/48 einen Vergleichstext erstellen, der für die Evangelischen eine Rückkehr zum Katholizismus vorsah. Nur wenige Zugeständnisse wurden ihnen gewährt; jene auch nur bis zur Abhaltung eines Konzils. Da es sich hierbei also um eine Zwischenlösung handelte, wurde das 1548 erlassene Gesetz unter dem Namen Augsburger Interim bekannt.

In den Gebieten, wo die kaiserlichen Truppen standen, wurde das Interim schnell und manches Mal unter Einsatz von Gewalt eingeführt und renitente Prediger vertrieben. In den traditionell kaiserfernen Territorien und Städten des Nordens regte sich jedoch zäher Widerstand. Insbesondere die der Reichsacht unterliegende Stadt Magdeburg, die auch nach dem Schmalkaldischen Krieg dem Kaiser den Gehorsam verweigerte, sollte als ,Herrgotts Kanzlei‘ ein Zufluchtsort der radikalen und kompromisslosen Gnesiolutheraner werden. Sie nahmen für sich in Anspruch, angeführt durch Matthias Flacius, die lutherische Orthodoxie zu vertreten.

Besonders untersuchenswert ist die Art und Weise, wie Kurfürst Moritz von Sachsen mit dem Interim umging, da er wenig Interesse hegte, die nach lutherischem Vorbild reformierten Kircheneinrichtungen erneut in Frage zu stellen. Die grundsätzliche Kompromissbereitschaft, die seine Theologen - unter ihnen Philipp Melanchthon - an den Tag legten, um einerseits das Luthertum zu bewahren und andererseits den Frieden zu erhalten, rief Widerstand hervor. Die sächsischen Theologen hatten sich aufgrund ihrer Verhandlungsbereitschaft in den Augen der Gnesiolutheraner als Handlanger von Papst und Kaiser erwiesen. Matthias Flacius und seine Mitstreiter entfesselten eine Flugschriftenoffensive, wie sie bis dahin beispiellos gewesen war. Für diese Resistenz wurde Magdeburg 1550/51 durch Moritz von Sachsen in seiner Funktion als Exekutor der Reichsacht belagert. Angesichts dieser Zeitumstände sah Flacius die sukzessive Einführung des Papsttums und die Zersetzung der evangelischen Kirche drohen. ${ }^{3}$

Aktuell führt das näher rückende Jubiläum ,500 Jahre Reformation - Luther 2017` Öffentlichkeit und Geschichtsforschung zu einer verstärkten Beschäftigung

und die Wittenberger Kapitulation, in: Reinhardt Eigenwill (Hg.), Zäsuren sächsischer Geschichte, Beucha 2010, S. 95-117; Gabriele Haug-Moritz, „Ob wir uns auch mit Gott / Recht und gutem Gewissen / wehren mögen / und Gewalt mit Gewalt vertreiben?". Zur Widerstandsdiskussion des Schmalkaldischen Krieges 1546/47, in: Luise Schorn-Schütte (Hg.), Das Interim 1548/50. Herrschaftskrise und Glaubenskonflikt (Schriften des Vereins für Reformationsgeschichte 203), Gütersloh 2005, S. 488-509; DiEs., Der Schmalkaldische Krieg. Ein kaiserlicher Religionskrieg?, in: Franz Brendle/ Anton Schindling (Hg.), Religionskriege im Alten Reich und in Alteuropa, Münster 2006, S. 93-105; OskaR Waldeck, Die Publizistik des Schmalkaldischen Krieges I und II, in: Archiv für Reformationsgeschichte 7 (1909/10), S. $1-55$ und 8 (1910/11), S. 44133.

3 Vgl. in übersichtlicher Form Felix Engel, ,Revoluzzer' oder ,Leisetreter'? Der Weg zum Theologentag von Jüterbog 1548, Jüterbog 2013. 
mit Luthers Forderungen nach einer Erneuerung der Kirche und den daraus folgenden gesellschaftlichen und politischen Verwerfungen. Im Zuge dessen rückt das Blickfeld auch zunehmend auf die Spätreformation. Ein Trend wurde angestoßen, der die Erforschung jener Zeit und der ihr innewohnenden Dynamik zum Gegenstand hat und sich bereits in zahlreichen Studien niederschlägt. Die alleinige Fixierung auf den ,großen Reformator" wird der Ausbildung der deutschen und europäischen Konfessionskulturen im Laufe des 16. Jahrhunderts eben nicht gerecht. Außerdem ist insbesondere für das Verhältnis von Politik und Religion eine ungleich größere Sensibilität zu beobachten; ihre Verzahnung und Interdependenz bildet mittlerweile ein zentrales Thema der Frühneuzeitforschung. ${ }^{4}$

Grundlegend sind die Ausführungen Luise Schorn-Schüttes und Robert von Friedeburgs, welche die Frage nach dem Verhältnis von Politik und Religion mit derjenigen nach Tradition und Innovation verbinden. Sie postulieren für die Frühe Neuzeit eine „innovative Kraft der Tradition“. Mit der Reformation und der sich anschließenden Konfessionalisierung sei gerade der Verknüpfung von Politik und Religion deshalb Vorschub geleistet worden, weil nach damaligem Verständnis eine rechtmäßige Obrigkeit nur eine christliche sein konnte. Damit war die Stärkung traditioneller Herrschaftsrechte eben dieser politischen Theologie zu verdanken. So sahen sich die Politiker während der Konstituierung der Konfessionen dazu gezwungen, theologisch Position zu beziehen, während den Geistlichen mit ihrer Einbindung in das weltliche Leben eine politische Rolle zukam. Eine Autonomie der beiden Bereiche kann also von vornherein nicht angenommen werden. ${ }^{5}$

Die Geschichte des Christentums beinhaltet grundsätzlich eine Verschränkung mit der Politik und zwar wegen eines bereits auf Erden zu realisierenden Heilsanspruchs, indem die Ausübung weltlicher Macht mit jenem religiösen Auftrag legitimiert wird. Sind nun aber mehrere Heilsangebote vorhanden, die jeweils für sich allein die Verkündung göttlichen Willens unter Ausschluss Andersgläubiger in

4 Zentrale Werke sind u. a. Irene Dingel/Günther Wartenberg (Hg.), Politik und Bekenntnis. Die Reaktionen auf das Interim von 1548 (Leucorea-Studien zur Geschichte der Reformation und der Lutherischen Orthodoxie 8), Leipzig 2006; Thomas Kaufmann, Das Ende der Reformation. Magdeburgs „Herrgotts Kanzlei“ (15481551/52) (Beiträge zur historischen Theologie 123), Tübingen 2003; ANJA MorITz, Interim und Apokalypse. Die religiösen Vereinheitlichungsversuche Karls V. im Spiegel der magdeburgischen Publizistik. 1548-1551/52 (Spätmittelalter, Humanismus, Reformation 47), Tübingen 2009; Schorn-Schüтte, Das Interim 1548/50 (wie Anm. 2). Auch das von Irene Dingel geleitete Forschungsprojekt Controversia et Confessio zeigt beispielhaft, dass weitere Aspekte der Spätreformation eine eingehende Analyse verdienen: http://www.controversia-et-confessio.adwmainz.de [Zugriff am 6. Oktober 2014]. Siehe zum Konzept ausführlich Henning P. Jürgens, Druckschriften in den theologischen Debatten des späteren 16. Jahrhunderts. Die Datenbank der Mainzer Quellenedition zur Bekenntnisbildung und Konfessionalisierung (1548-1580), in: Dingel/Wartenberg, Politik und Bekenntnis, S. 125-138.

5 Vgl. Robert von Friedeburg/Luise Schorn-Schütte, Einleitung. Politik und Religion: Eigenlogik oder Verzahnung?, in: Dies. (Hg.), Politik und Religion. Eigenlogik oder Verzahnung? Europa im 16. Jahrhundert (Historische Zeitschrift, Beiheft N.F. 45), München 2007, S. 1-12, hier S. 1-6, Zitat S. 2. 
Anspruch nehmen, sind in der nicht säkularisierten Gesellschaft Konflikte kaum vermeidbar. Dass dies in besonderem Maße auf das 16. Jahrhundert zutrifft, in welchem die relative theologische Homogenität in Mitteleuropa langfristig gebrochen wurde, kommt bei der Betrachtung der Interimsstreitigkeiten zum Vorschein.

Vor dem Hintergrund des geschärften Verständnisses für die Verzahnung von Politik und Religion lohnt es sich wohl, den Entstehungsprozess der Leipziger Landtagsvorlage in der zweiten Jahreshälfte 1548 zu betrachten. Die Genese, Beratung und (Nicht-)Beschließung dieses als religiöses Vergleichswerk angedachten Textes barg aufgrund der Verknüpfung theologischer Lehrstreitigkeiten und machtpolitischer Einflussnahme entgegen der ursprünglichen Intention gänzlich neues Konfliktpotenzial, diesmal innerhalb des Luthertums. Die Gemüter erhitzten sich darüber, ob Kompromisse in Religionssachen eingegangen werden dürften, um in der Welt keine oder zumindest weniger Verfolgung zu erleiden. Immerhin ist die Bedeutung religiöser Fragen und Deutungsmuster für die beginnende Frühe Neuzeit nicht zu unterschätzen.

Bis etwa auf eine ältere Darstellung von Simon Ißleib ${ }^{6}$ wird die Entstehung der Leipziger Landtagsvorlage eher übergreifend im Zusammenhang mit dem Augsburger Interim oder mit dem Streit um die Adiaphora thematisiert. ${ }^{7}$ Zuweilen werden auch spezielle Aspekte beleuchtet, ${ }^{8}$ oder die Genese des kursächsischen Religionsgesetzes wird in Betrachtungen zu einzelnen daran beteiligten Akteuren

6 Vgl. Simon Issleib, Das Interim in Sachsen 1548-1552, in: NASG 15 (1894), S. 193-236. - Bisher leider nicht gedruckt: Johannes Herrmann, Augsburg - Leipzig - Passau. Das Leipziger Interim nach Akten des Landeshauptarchivs Dresden 1547-1552, masch. Diss. Leipzig 1966.

7 Vgl. beispielsweise Irene Dingel (Hg.), Der Adiaphoristische Streit (1548-1560) (Controversia et Confessio 2), Göttingen 2012; Henning P. Jürgens, Flacius gegen Melanchthon. Die „Herrgotts Kanzlei“ und der Kampf gegen das Interim, in: Mariano Delgado/Volker Leppin/David Neuhold (Hg.), Ringen um die Wahrheit. Gewissenskonflikte in der Christentumsgeschichte (Studien zur christlichen Religions- und Kulturgeschichte 15), Stuttgart 2011, S. 203-220; Kaufmann, Das Ende der Reformation (wie Anm. 4); ERnst Koch, Der Ausbruch des adiaphoristischen Streits und seine Folgewirkungen, in: Dingel/Wartenberg, Politik und Bekenntnis (wie Anm. 4), S. 179190; Albrecht Pius Luttenberger, Glaubenseinheit und Reichsfriede. Konzeptionen und Wege konfessionsneutraler Reichspolitik 1530-1552 (Kurpfalz, Jülich, Kurbrandenburg) (Schriften der Historischen Kommission bei der Bayerischen Akademie der Wissenschaften 20), Göttingen 1982; Joachim Mehlmausen, Der Streit um die Adiaphora, in: Martin Brecht/Reinhard Schwarz (Hg.), Bekenntnis und Einheit der Kirche. Studien zum Konkordienbuch, Stuttgart 1980, S. 105-128; Moritz, Interim und Apokalypse (wie Anm. 4); Andreas Waschiüsch, Alter Melanchthon. Muster theologischer Autoritätsstiftung bei Matthias Flacius Illyricus (Forschungen zur Kirchenund Dogmengeschichte 96), Göttingen 2008.

8 Vgl. beispielsweise Nikolaus Müller, Zur Geschichte des Interims, in: Jahrbuch für Brandenburgische Kirchengeschichte 5 (1908), S. 51-171; Günther Wartenberg, Das Augsburger Interim und die Leipziger Landtagsvorlage zum Interim, in: Dingel/Wartenberg, Politik und Bekenntnis (wie Anm. 4), S. 16-32. 
eingebettet. ${ }^{9}$ Ergänzend dazu erhebt der vorliegende Beitrag den Anspruch, den Entstehungsprozess der Leipziger Landtagsvorlage anhand der vorhandenen Quellen nachzuzeichnen und damit die Herausbildung der innerlutherischen Fraktionen um das Jahr 1548 zu beleuchten. Um die Mechanismen dieses Differenzierungsprozesses verstehbar zu machen, wird bei den handelnden Protagonisten der Religionsgespräche und Versammlungen, ihren Standpunkten, Motiven, Einflussmöglichkeiten und gegenseitigen Abhängigkeiten angesetzt. ${ }^{10}$ Davon ausgehend werden jene Theologen, Juristen und Politiker im Personengeflecht verortet sowie Verschiebungen in ihren Positionen infolge der abgehaltenen Versammlungen und Gespräche nachvollzogen. Hierbei soll vor allem erhellt werden, ob die jeweiligen Akteure vordergründig einer politischen oder einer religiösen Motivation folgten und inwiefern sich die konstatierte Verknüpfung von Politik und Bekenntnis auf die Genese der Leipziger Artikel auswirkte.

Eine Einschränkung muss dennoch vorgenommen werden: Für die ernestinische Positionierung zu Interim und Adiaphora - auch in Abgrenzung zum albertinischen Kursachsen - fehlt hier der Raum. Das entbehrt aber insofern einer besonderen Problematik, da die ernestinischen Theologen auf die Entstehung der Leipziger Landtagsvorlage keinen direkten Einfluss zu nehmen vermochten. ${ }^{11}$

9 Vgl. beispielsweise Oliver K. Olson, Matthias Flacius and the Survival of Luther's Reform (Wolfenbütteler Abhandlungen zur Renaissanceforschung 20), Wiesbaden 2002; Ernst-Otto Reichert, Amsdorff und das Interim. Kommentierte Quellenedition mit ausführlicher historischer Einleitung (Leucoreastudien zur Geschichte der Reformation und der Lutherischen Orthodoxie 14), Leipzig 2011; Heinz Scheible, Melanchthon. Eine Biographie, München 1997; Günther Wartenberg, Philipp Melanchthon und die sächsisch-albertinische Interimspolitik, in: Lutherjahrbuch 55 (1988), S. 60-82.

10 Um sich der Thematik über die handelnden Protagonisten zu nähern, ist es unverzichtbar, deren Schriftwechsel zu sichten: Politische Korrespondenz des Herzogs und Kurfürsten Moritz von Sachsen, hrsg. von der Historischen Kommission der Sächsischen Akademie der Wissenschaften zu Leipzig, 6 Bde., Leipzig/Berlin 1900-2006 (im Folgenden: PKMS); Karl GotTlieb Bretschneider/Heinrich Ernst Bindseil (Hg.), Corpus Reformatorum. Philippi Melanthonis Opera Quae Suppersunt Omnia, 28 Bde., Halle/Braunschweig 1834-1860 (im Folgenden: CR). Seit 1977 hat sich der Melanchthon-Forscher Heinz Scheible zum Ziel gesetzt, den Briefwechsel des Reformators mit Sorgfalt $\mathrm{zu}$ registrieren und $\mathrm{zu}$ edieren: Heinz Scheible (Hg.), Melanchthons Briefwechsel. Kritische und kommentierte Gesamtausgabe. Regesten, 14 Bde., Stuttgart-Bad Cannstatt 1977 ff. (im Folgenden: MBW); Ursula MachoczeK (Bearb.), Deutsche Reichstagsakten unter Kaiser Karl V. Der Reichstag zu Augsburg 1547/48 (Deutsche Reichstagsakten. Jüngere Reihe 18), 3 Teilbde., München 2006 (im Folgenden: RTA J.R. 18). - Die mannigfaltigen Flugschriften, in denen Stellung zu den jeweiligen Streitfragen genommen wurde, müssen ebenso einbezogen werden. Hilfreich ist in diesem Zusammenhang das Verzeichnis der im deutschen Sprachbereich erschienenen Drucke des 16. Jahrhunderts (VD 16): http://www.VD16.de [Zugriff am 6. Oktober 2014].

11 Zudem kann auf fundierte Literatur verwiesen werden: JoAchim BaUer, Der Kampf um das „wahre“ Luthertum. Jena und Wittenberg 1548, in: Schorn-Schütte, Das Interim 1548/50 (wie Anm. 2), S. 277-291; Daniel GeHRT, Ernestinische Konfessionspolitik. Bekenntnisbildung, Herrschaftskonsolidierung und dynastische Identitätsstiftung vom 


\section{Sachsen, der Schmalkaldische Krieg und das Augsburger Interim}

Der albertinische Herzog Moritz von Sachsen, eine der umstrittensten Persönlichkeiten der frühneuzeitlichen Reichsgeschichte, hatte im Schmalkaldischen Krieg für den Kaiser und gegen seinen ernestinischen Vetter Kurfürst Johann Friedrich von Sachsen und seinen Schwiegervater Landgraf Philipp von Hessen gekämpft. Da mit der Schlacht bei Mühlberg vom 24. April 1547 Johann Friedrich den Krieg verlor, musste er in der Wittenberger Kapitulation vom 19. Mai die Kurwürde nebst umfangreichen Territorien an Moritz übertragen. ${ }^{12}$ Die Versprechen, die Kaiser Karl V. und König Ferdinand gegeben hatten, um Moritz für ein militärisches Engagement auf ihrer Seite zu überzeugen, sollten sich als folgenschwer für die Entwicklung nach dem Krieg erweisen.

Moritz von Sachsen hatte gegenüber den Konfliktparteien zunächst eine ambivalente Haltung eingenommen. Der junge Wettiner entsprang der 1485 entstandenen albertinischen Linie und herrschte demzufolge über die Markgrafschaft Meißen und Gebiete um Leipzig und im Norden Thüringens, während die ernestinische Linie über die Landgrafschaft Thüringen und den Kurkreis um Wittenberg verfügte. ${ }^{13}$ Das sich generierende Konkurrenzverhältnis zwischen Herzog Moritz und Kurfürst Johann Friedrich wusste der Kaiser für seine Zwecke zu nutzen. Indem er konfessionelle Kriegsgründe leugnete, wollte er militärisch potente protestantische Fürsten für sein Kriegsvorhaben gewinnen.

Bereits am 19. Juni 1546 konnte Moritz vertraglich an Kaiser und König gebunden werden. Er versicherte seine Beihilfe zur Herstellung von Frieden und Recht sowie die Anerkennung und Beschickung des Trienter Konzils. Bis dahin sollte der religiöse Status quo im albertinischen Sachsen gelten. ${ }^{14}$ Die katholischen Stifter Magdeburg und Halberstadt wurden unter albertinischen Schutz gestellt. ${ }^{15}$

Augsburger Interim 1548 bis zur Konkordienformel 1577 (Arbeiten zur Kirchen- und Theologiegeschichte 34), Leipzig 2011; Thomas Kaufmann, Die Anfänge der Theologischen Fakultät Jena im Kontext der „innerlutherischen“ Kontroversen zwischen 1548 und 1561, in: Volker Leppin/Georg Schmidt/Sabine Wefers (Hg.), Johann Friedrich I. - der lutherische Kurfürst (Schriften des Vereins für Reformationsgeschichte 204), Gütersloh 2006, S. 209-258; ERnst KocH, Theologische Aspekte der ernestinischen Reaktionen auf das Interim, in: Schorn-Schütte, Das Interim 1548/50 (wie Anm. 2), S. 312-330.

12 Vgl. Simon Issleib, Die Wittenberger Kapitulation von 1547, in: NASG 12 (1891), S. 272-297.

13 Vgl. Katrin Keller, Landesgeschichte Sachsen (UTB 2291), Stuttgart 2002, S. 68-70; Volker Graupner, Die Leipziger Teilung von 1485, in: Hans Hoffmeister/Volker Wahl (Hg.), Die Wettiner in Thüringen. Geschichte und Kultur in Deutschlands Mitte (Schriften des Thüringischen Hauptstaatsarchivs Weimar 2), Arnstadt/Weimar 1992, S. 86-93.

14 Vgl. PKMS 2, Nr. 922, S. 660-664: Vertrag zwischen Kaiser Karl V., König Ferdinand und Herzog Moritz, Regensburg, 19. Juni 1546, hier S. 661 f.

15 Vgl. ebd., S. 663 f. - Vgl. dazu auch PKMS 2, Nr. 923, S. 665-667: Ernennungsurkunde Karls V. für Herzog Moritz zum Konservator und Exekutor der Stifter Magdeburg und Halberstadt, Regensburg, 19. Juni 1546. 
Welche Ziele verfolgte Moritz darüber hinaus im Frühsommer 1546? Mit ziemlicher Sicherheit die weitere Konsolidierung der bestehenden Herrschaft und auch eine Ausweitung derselben. Eine mögliche Übertragung der sächsischen Kur auf seine Linie war bei den Verhandlungen zwar thematisiert worden, doch der Albertiner wollte keinesfalls seine offizielle Neutralität aufgeben. Vielmehr strebte er vorerst danach, durch Vermittlung zwischen Kaiser und Schmalkaldenern, denen er konfessionell wie verwandtschaftlich eng verbunden war, den Frieden zu erhalten. Die Eindringlichkeit, mit der Moritz seine Vermittlungsangebote unterbreitete, legt nahe, dass es sich nicht um bloße diplomatische Winkelzüge handelte, sondern um ein ernstes Anliegen. ${ }^{16}$ Dies musste jedoch an der unbedingten Bereitschaft des Kaisers scheitern, einen Krieg zu beginnen: Als Voraussetzung zur Klärung der Religionsfrage sollten die Machtverhältnisse im Reich neu geordnet werden. Karl V. gab Moritz immerhin die Versprechen: S. F. Gn. sollen wider die bestetigeten erbeinigungen und auch wider die religion zu thun nicht schuldig sein. ${ }^{17}$

Dabei sollte es aber nicht bleiben. Denn Moritz wurde am 8. August 1546 mit der Exekution der Reichsacht gegen die Hauptleute des Schmalkaldischen Bundes, auf denen wegen angeblich aufrührerischen Verhaltens die Reichsacht lastete, betraut. ${ }^{18}$ Nach längeren Verzögerungen seitens des Herzogs ging er mit König Ferdinand schließlich am 14. Oktober ein Bündnis ein, das gegen Johann Friedrich und auf die Besetzung Kursachsens zielte. ${ }^{19}$ In diesem Zusammenhang war auch die Übertragung der Kurwürde auf den Albertiner im Gespräch gewesen. ${ }^{20}$ Den Vorrang der Religion vor der weltlichen Autorität hatte Moritz anerkannt. Wegen der Zusicherung des Kaisers, den Krieg nicht aufgrund religiöser Beweggründe zu führen, schlossen sich für den protestantischen Herzog dieses Prinzip und seine Kriegsteilnahme nicht gegenseitig aus. Ohnehin war Moritz seit dem Befehl auf Achtvollstreckung kaum noch Handlungsfreiheit gegeben, sodass er nicht als der skrupellose Machtpolitiker, der sich über die zeittypischen Konventionen zur Friedenssicherung konsequent hinwegsetzte, zu charakterisieren ist: „Mehr

16 Vgl. zu den Entstehungsumständen und Inhalten des Vertrags vom 19. Juni 1546 ERICH Brandenburg, Der Regensburger Vertrag zwischen den Habsburgern und Moritz von Sachsen (1546), in: Historische Zeitschrift 80 (1898), S. 1-42.

17 PKMS 2, Nr. 928, S. 673 f.: Albertinische Aufzeichnung über die Unterredung zwischen Karl V., König Ferdinand und Herzog Moritz, Regensburg, 20. Juni 1546, hier S. 674.

18 Vgl. PKMS 2, Nr. 973, S. 760-762: Kaiser Karl V. an Herzog Moritz und dessen Landstände, Landshut, 8. August 1546. Bei Moritz kam das Schreiben am 18. August 1546 an.

19 Vgl. PKMS 2, Nr. 1023, S. 872-877: Offensiv- und Defensivbündnis zwischen König Ferdinand und Herzog Moritz, Prag, 14. Oktober 1546.

20 Vgl. PKMS 2, Nr. 1026, S. 883-886: Christof von Carlowitz an Herzog Moritz, Prag, 16. Oktober 1546, hier S. 886. Zur Kurfrage vgl. außerdem Reichert, Amsdorff und das Interim (wie Anm. 9), S. 76 f. 
unfreiwillig wurde Moritz in ein Bündnis mit dem Kaiser gezogen. "21 Ende des Monats rückten sie dann gemeinsam auf Kursachsen vor. Lange Zeit sollte Moritz dafür das Stigma des ,Judas von Meißen“ anhaften.

„Mühlberg war die Voraussetzung für alles Weitere.“22 Nach dem militärischen Sieg konnte Karl V. zu einer endgültigen Klärung in der Religionsfrage schreiten, ohne durch erbitterten Widerstand seine Pläne schon im Ansatz scheitern zu sehen. Dem Kaiser stand sehr wohl der Sinn danach, die Wiedereinführung des alten Glaubens per Befehl zu verfügen,23 „allein selbst in jener siegreichen Zeit fehlte ihm dazu die Kraft und Macht“.24 Die Entscheidung, eine Lösung für das Konfessionsproblem auf einem Reichstag beschließen zu lassen, war bereits im Frühjahr 1547 auf Anraten Ferdinands gefallen und offenbart das Ansinnen, mit den Ständen gemeinsam ein tragfähiges Einigungsgesetz zu verabschieden. So nahm Karl V. unmittelbar nach Kriegsende keine Veränderungen in der Religion für die besetzten Territorien vor, um die bisher mit ihm verbündeten Protestanten nicht gegen sich aufzubringen. Der Kaiser soll im besetzten Wittenberg geäußert haben: Haben wir doch nichts gewandelt jnn der Religion jnn den boch deudtschen Landen, warumb solten wirs denn bie thun?25 Auch besuchte er das Grab Luthers und ließ es unberührt. ${ }^{26}$

Geschickt aber hatte Karl V. mit der Kriegsinvolvierung Herzog Moritz' und dessen Ausrufung zum Kurfürsten am 4. Juni 1547 im Lager vor Wittenberg27 die Verschärfung des innerwettinischen Konflikts initiiert. Das sollte bedeutende Auswirkungen auf die macht- und religionspolitische Konsolidierung der beiden Territorialstaaten nach sich ziehen. Moritz musste daran gelegen sein, den Vertrauensverlust bei seinen alten und neuen Untertanen zu kompensieren. Schon am 6. Juni, dem Tag seines Einzugs in das vom Kaiser geräumte Wittenberg, wurde er von den Vertretern der Stadtbürgerschaft um die Wiedereröffnung der Universität angehalten, später baten auch die kursächsischen Stände darum. ${ }^{28}$ Denn die Lehranstalt war am 6. November 1546 infolge des Einfalls von Moritz ins ernestinische

21 Christian Winter, Sachsen als europäische Großmacht? Moritz von Sachsen als Führer der Opposition gegen Kaiser Karl V., in: Denkströme 4 (2010), S. 105-120, hier S. 109.

22 Reichert, Amsdorff und das Interim (wie Anm. 9), S. 87.

23 Vgl. Alfred Kohler (Hg.), Quellen zur Geschichte Karls V. (Ausgewählte Quellen zur deutschen Geschichte der Neuzeit 15), Darmstadt 1990, Nr. 93, S. 362-367: Brief Karls V. an Ferdinand I., Heilbronn, 9. Januar 1547; Nr. 94, S. 367-370: Brief Ferdinands an Karl V., Prag, 18. Januar 1547.

24 Simon Issleib, Moritz von Sachsen 1547-1548, in: NASG 13 (1892), S. 188-220, hier S. 198.

25 Kohler, Quellen zur Geschichte Karls V. (wie Anm. 23), Nr. 97, S. 376-380: Johann Bugenhagens Bericht über Belagerung und Übergabe Wittenbergs, Auszug, hier S. 378.

26 Vgl. Heinz Scheible, Melanchthon rettet die Universität Wittenberg, in: Aufsätze zu Melanchthon (Spätmittelalter, Humanismus, Reformation 49), Tübingen 2010, S. 253276, hier S. 259.

27 Vgl. Issleib, Moritz von Sachsen 1547-1548 (wie Anm. 24), S. 188.

28 Vgl. KoHLER, Quellen zur Geschichte Karls V. (wie Anm. 23), S. 379. 
Sachsen geschlossen worden.29 Betroffen war davon auch Philipp Melanchthon, der mit Familie und Freunden eine mehrwöchige Odyssee durch Niedersachsen durchlebte. ${ }^{30}$ Er hatte sich dazu gezwungen gesehen, weil er während des Krieges an der Ausformulierung der protestantischen Notwehrlehre ${ }^{31}$ und der publizistischen Kriegsführung beteiligt gewesen war und daher den Missmut der Kaiserlichen auf sich gezogen hatte. ${ }^{32}$

Der neue sächsische Kurfürst und der Praeceptor Germaniae, die sich zuvor misstrauisch beäugt hatten, gingen nun mit der Wiedereröffnung der Wittenberger Universität eine Symbiose ein. Melanchthon wollte das dortige Lehrkorpus erhalten, sein Lebenswerk fortsetzen sowie seine theologische Autorität behaupten. Moritz sicherte auf dem Leipziger Landtag im Juli 1547 den Erhalt, die Lehrfreiheit sowie die Versorgung beider albertinischer Universitäten, Leipzig und Wittenberg, zu und versprach die Bewahrung des evangelischen Glaubens. Zudem sollte die Festigung der Reformation durch eine bessere Besoldung für Geistliche, die Verabschiedung einer einheitlichen Kirchenordnung und die Beibehaltung aller drei Konsistorien vonstattengehen. Das waren gute Gründe für Melanchthon, die Vorlesungen in seiner alten Wirkungsstätte am 24. Oktober wieder aufzunehmen. ${ }^{33}$ Moritz konnte durch die Bindung Melanchthons den Befürchtungen der Protestanten entgegentreten sowie seine neue politische Macht auf die Religionserhaltung gründen, indem er das gängige Bild des die Religion schützenden Herrschers bediente.

Infolge des gewonnenen Krieges berief Karl V. für den 1. September 1547 einen Reichstag nach Augsburg ein. Im Mittelpunkt stand für ihn und seine Berater die Reunion der abendländischen Christenheit durch die allgemeine Anerkennung und Beschickung des Trienter Konzils. Doch die Hoffnungen auf das Konzil zerschlugen sich, da dieses, um Druck auf den Kaiser auszuüben, am 11. März 1547 seine eigene Verlegung nach Bologna, das anders als Trient außerhalb der Reichsgrenzen lag, beschlossen hatte. Dies stand den Vorstellungen der Protestanten entgegen, innerhalb des Reiches zu einer Lösung zu gelangen, zumal sie argwöhn-

29 Vgl. ausführlich Thomas Töpfer, Die Leucorea am Scheideweg. Der Übergang von Universität und Stadt Wittenberg an das albertinische Kursachsen 1547/48. Eine Studie zur Entstehung der mitteldeutschen Bildungslandschaft (Beiträge zur Leipziger Universitäts- und Wissenschaftsgeschichte 3), Leipzig 2004.

30 Vgl. Scheible, Melanchthon rettet die Universität Wittenberg (wie Anm. 26), S. 257261.

31 So bei Justus Menius, Von der Notwehr vnterricht. Nützlich zu lesen, Wittenberg 1547 (VD 16: M 4592).

32 Vgl. Scheible, Melanchthon rettet die Universität Wittenberg (wie Anm. 26), S. 256 f.

33 Vgl. Bauer, Der Kampf um das „wahre“ Luthertum (wie Anm. 11), S. 281-283; Issleib, Moritz von Sachsen 1547-1548 (wie Anm. 24), S. 189-191, 194-196; SCHEIbLe, Melanchthon rettet die Universität Wittenberg (wie Anm. 26), S. 261-263, 269-273; Wartenberg, Philipp Melanchthon (wie Anm. 9), S. 64-67. - Zu den Landtagsverhandlungen in Leipzig vgl. vor allem PKMS 3, Nr. 673-710, S. 463-499, insbesondere Nr. 691, S. 483-485: Antwort von Moritz auf die Bedenken (Landgebrechen) der Ritterschaft, Leipzig, Mitte Juli 1547. 
ten, durch den Vorsitz des Papstes könnten die Lehrentscheidungen parteiisch beeinflusst werden. Schon im Februar 1547 hatte Ferdinand seinem Bruder vorgeschlagen, eine provisorische Kirchenreform für das Reich ausarbeiten zu lassen, die sowohl von den Protestanten angenommen als auch vom Papst toleriert werden würde. Jener Weg wurde nun weiterverfolgt, denn eine baldige religiöse Einheit, die durch das Trienter Konzil nicht so zügig zu erreichen war, erschien für König und Kaiser als Garant für den Erhalt des Friedens und der politischen Ordnung. ${ }^{34}$

Da mehrere Vermittlungsbemühungen auf dem Reichstag an der Unversöhnlichkeit der Verhandlungspartner scheiterten, musste der Kaiser die Verantwortlichkeit bald in die Hände derer legen, denen die Reunion eine Herzensangelegenheit war. Dafür berief er mit dem Naumburger Bischof Julius Pflug und dem Mainzer Weihbischof Michael Helding zwei Reformkatholiken sowie als einzigen Protestanten den brandenburgischen Hofprediger Johann Agricola in eine Kommission, die ab Anfang Februar 1548 an einem Vergleichstext arbeitete. So nahm der Kaiser mit dieser Besetzung bereits Einfluss auf die zu erzielenden Ergebnisse. Gleichwohl wurden zu einem späteren Zeitpunkt weitere katholische, weniger kompromisswillige Theologen hinzugezogen, ${ }^{35}$ um offenbar sicherzustellen, „daß Pflug und Helding in ihrer Verständigungsbereitschaft gegenüber den Protestanten nicht etwa zu weit gingen“.36

All die dann im Augsburger Interim enthaltenen Zugeständnisse an die Protestanten waren bereits in einer Ursprungsversion des katholischen Vermittlungstheologen Pflug angedacht gewesen, ${ }^{37}$ sodass dem einzigen in die Beratungen involvierten Protestanten, Agricola, die Aushandlung jener Punkte nicht als Verdienst angerechnet werden kann. ${ }^{38}$ Doch welche Funktion hatte der Brandenburger zu erfüllen, wenn weite Teile des Vergleichstextes schon fertig waren?

Der Wille des Kaisers war es, Katholiken und Protestanten für sein Einigungsvorhaben zu gewinnen. Die evangelische Zustimmung für einen allein von Katholiken ausgearbeiteten Text wäre womöglich äußerst gering ausgefallen. Doch von dem erst auf dem Reichstag rechtskräftig mit der sächsischen Kurwürde belehnten Albertiner Moritz ${ }^{39}$ und dessen Theologen konnte Karl V. in der Religionsfrage

34 Vgl. Luttenberger, Glaubenseinheit und Reichsfriede (wie Anm. 7), S. 426-428; Horst Rabe, Reichsbund und Interim. Die Verfassungs- und Religionspolitik Karls V. und der Reichstag von Augsburg 1547/48, Köln 1971, S. 190 f.

35 Vgl. Horst Rabe, Zur Entstehung des Augsburger Interims 1547/48, in: Archiv für Reformationsgeschichte 94 (2003), S. 6-104, hier S. 54 f., insbesondere Anm. 149 f.

36 Ebd., S. 55.

37 Vgl. Gustav Kawerau, Johann Agricolas Antheil an den Wirren des Augsburger Interim, in: Zeitschrift für Preußische Geschichte und Landeskunde 17 (1880), S. 398463, hier S. 411; Joachim Mehlhausen, Interim, in: Gerhard Müller/Gerhard Krause (Hg.), Theologische Realenzyklopädie, Bd. 16, Berlin/New York 1987, S. 230-237, hier S. 231 f.; MoriTz, Interim und Apokalypse (wie Anm. 4), Tübingen 2009, S. 118.

38 Vgl. Kawerau, Johann Agricolas Antheil (wie Anm. 37), S. 412.

39 Zur am 14. Februar 1548 erfolgten Belehnung vgl. z. B. Issleib, Moritz von Sachsen 1547-1548 (wie Anm. 24), S. 204-206; Geheimes Staatsarchiv Preußischer Kulturbesitz 
kaum Entgegenkommen erwarten, da Moritz nach wie vor den Standpunkt vertrat, ohne Zustimmung der kursächsischen Landstände aufgrund der ihnen gegebenen Versprechen keine Konzessionen bewilligen oder von seinen dezidiert protestantischen Konzilsvorstellungen ablassen zu wollen. Für den bereits als ,Judas von Meißen' geschmähten Kurfürsten wäre ein Nachgeben gegenüber dem Kaiser in dieser Sache mit schwerwiegenden innenpolitischen Folgen verbunden gewesen. ${ }^{40}$ Zudem galt Sachsen als Stammland der Reformation, während etwa im lutherischen Brandenburg eine äußerst konservative, altkirchliche Zeremonien festschreibende Kirchenordnung in Kraft war. Der brandenburgische Kurfürst Joachim II. und sein Hofprediger Agricola waren für ihre Einigungsbereitschaft und prokaiserliche Einstellung bekannt - der Theologe noch mehr als sein Herr -, sodass Agricola die Alibi-Funktion des,Quotenprotestanten' in der maßgeblichen Interimskommission auszufüllen hatte, der er sich mit Begeisterung annahm. Es ist relativ sicher, dass bis auf einige Marginalien der Hofprediger Joachims II. lediglich für die Übersetzung des Interims vom Lateinischen ins Deutsche verantwortlich zeichnete. ${ }^{41}$ So wird man Agricola vertrauen können, wenn er später einmal äußerte: [I]ch glaube, das Interim war gemacht, ebe wir nach Augsburg kamen. ${ }^{42}$

Der ausgearbeitete Vergleichstext umfasste insgesamt 26 Artikel, von denen der wohl wichtigste die Rechtfertigungslehre betraf. Die Väter des Augsburger Interims meinten mit der Konstatierung einer zweifachen Gerechtigkeit (duplex iustificatio) einen passablen Kompromiss gefunden zu haben: Also khomen zusamen Christi verdienst und die eingegebne gerechtigkait, zu welcher wir verneuert werden durch die gab der liebe. ${ }^{43}$ Die göttliche Liebe, die dem Menschen ins Herz gegeben wird, sei verantwortlich für das Streben des Gläubigen nach dem Guten und Rechten. Aber der verdienst Christi, das er der gerechtigkait, so in uns ist, ein ursach sey, ${ }^{44}$ offenbart das Trachten, evangelische und katholische Rechtfer-

(im Folgenden: GStA PK), I. HA, Rep. 10 Reichstagsverhandlungen, Nr. I Fortsetzung des Reichstags zu Augsburg, Fasz. 2 Belehnung des Kurfürsten Moritz, 1548; PKMS 3, Nr. 1001, S. 734-736: Bericht über die Belehnung von Hz. Moritz mit der Kur von Sachsen, Augsburg, 24. Februar 1548. Vgl. des Weiteren ebd., Nr. 1002-1006, S. 736-740.

40 Vgl. PKMS 3, Nr. 830, S. 585 f.: Erklärung von Kf. Moritz vor Ks. Karl V., Augsburg, 18. Oktober 1547; Nr. 937, S. 673-675: Bericht über die Verhandlungen der alb. Landschaft in Torgau, 26. Dezember 1547; Nr. 938, S. 675-678: Erklärung von Kf. Moritz vor den Räten und Ständevertretern, 26. Dezember 1547; Nr. 942, S. 680-685: Antwort der Räte und Ständevertreter an Kf. Moritz, 31. Dezember 1547, hier S. 680 f.; Nr. 994, S. 723-725: Bedenken von Kf. Moritz zur Religionsänderung, nach dem 19. Februar 1548. - Vgl. weiterhin zur Haltung Moritz' IssLeIb, Moritz von Sachsen 1547-1548 (wie Anm. 24), S. 199-204.

41 Vgl. vor allem Kawerau, Johann Agricolas Antheil (wie Anm. 37), S. 400-407.

42 Zit. nach ebd., S. 413.

43 Joachim Mehlhausen (Hg.), Das Augsburger Interim. Nach den Reichstagsakten deutsch und lateinisch (Texte zur Geschichte der evangelischen Theologie 3), Neukirchen-Vluyn ${ }^{2} 1996$, S. 46. 
tigungslehre zusammenzubringen. Dieses Ansinnen wurde folglich versucht, für die Werkgerechtigkeit zu realisieren. Zwar wird zunächst ganz nach protestantischem Duktus festgestellt, dass Gott den mentschen gerecht macht nit auß den wercken der gerechtigkait, die der mentsch thuet, sonder nach seiner barmbertzigkait, und das lautter umbsunst, das ist, one seine verdienst, ${ }^{45}$ doch die gerechtigkait besteet durch den glauben, die hoffnung und die liebe, ${ }^{46}$ und Früchte dieser Liebe und Gnade seien eben die guten Werke, für die zeitlicher und ewiger Lohn zu erwarten sei. ${ }^{47}$ Nach dieser Lehre könne auf das Vollbringen guter Werke zur Erlangung des ewigen Lebens nicht verzichtet werden, seien sie doch zumindest mittelbarer Ausdruck des rechten Glaubens.

Die Artikel über die Kirche, ${ }^{48}$ die do ist die gemeinschafft und versamblung der christglaubigen, ${ }^{49}$ folgen dagegen ausnahmslos katholischen Vorstellungen, indem die sichtbare Kirche mit ihrer Mittlerfunktion hervorgehoben wird. Es wird ihr das Recht zugesprochen, falsche Lehren zu verwerfen und die Heilige Schrift auszulegen. Sie dürfe die Exkommunikation und den Gerichtszwang ausüben. ${ }^{50}$ Wenn ein Konzil etwas beschließe - und an dieser Stelle ist die Divergenz zur lutherischen Lehre augenscheinlich -, das ist zu achten, als bette es der beillig geist selbst geschlosen. ${ }^{51}$ Außerdem wird die alte Kirchenhierarchie festgeschrieben, deren Haupt der Papst ist, der den andern allen mit vollem gwalt fürgesetzt ist, zwar um scismata und trennung zu verbueten und unter Gebrauch seiner Gewalt nit zur zerstörung, sonder zur erbawung. ${ }^{52}$ Doch diese an die Protestanten gerichteten Konzessionen muten äußerst dehnbar an und widersprachen keinesfalls der katholischen Lehre. ${ }^{33}$ Die altgläubige Ausrichtung des Augsburger Interims wird unterstrichen durch die Festschreibung der sieben Sakramente sowie mit der Aufforderung zur Heiligenverehrung und Abhaltung von Seelenmessen. ${ }^{54}$

Der Artikel Vom opffer der me $\beta^{55}$ darf trotz Festhaltens am Opfercharakter der Messfeier nicht darüber hinwegtäuschen, dass eine offensichtliche Annäherung an protestantische Lehrvorstellungen angestrebt wurde. Da sich Jesus Chris-

45 Ebd., S. 48.

46 Ebd., S. 50.

47 Vgl. ebd., S. 54.

48 Vgl. ebd., S. 58-72. - Zur Gestalt der Kirche vgl. Herbert Sowade, Das Augsburger Interim. Das kaiserliche Religionsgesetz von 1548 in seiner politischen und theologischen Relevanz für eine Einung der Christen, Münster 1977, S. 146-179. Mehlmausen, Das Augsburger Interim (wie Anm. 43), S. 58.

50 Vgl. ebd., S. 60-68.

51 Ebd., S. 68.

52 Ebd., S. 72.

53 Dagegen sieht Rabe, Reichsbund und Interim (wie Anm. 34), S. 429 in den ekklesiologischen Artikeln „eine unverkennbare Nähe zu reformatorischem Denken“.

54 Vgl. Mehlhausen, Das Augsburger Interim (wie Anm. 43), S. 72-102, 122-135. - Zu den Sakramenten vgl. ausführlich Sowade, Das Augsburger Interim (wie Anm. 48), S. $180-271$.

55 Vgl. Mehlhausen, Das Augsburger Interim (wie Anm. 43), S. 102 f. - Zur Messe vgl. ausführlich SowADE, Das Augsburger Interim (wie Anm. 48), S. 272-295. 
tus bereits für alle Sünden der Menschen geopfert habe, könnten keine weiteren Sühneopfer erbracht werden, dan es ist volkomen; es wirdet auch nicht geringert oder ausgeschöpfft, dan es ist ewig. ${ }^{56}$ Demnach sei das Messopfer lediglich zu gedechtnus des bluetopffers eingesetzt und der kirchen befolhen, ${ }^{57}$ also ein Gedenkund Dankopfer. Der grundlegende Unterschied zur evangelischen Vorstellung der „memoria bzw. repraesentatio"58 liegt eher im Festhalten am Opferbegriff begründet und ist somit kaum inhaltlicher Natur. ${ }^{59}$

Nachdem die vorigen Bestimmungen die Lehrstreitigkeiten vergleichen sollten, wurde im letzten Artikel mit der Aufrichtung der alten Zeremonien die Herstellung der äußeren Einheit der Kirche verfügt. ${ }^{60}$ Die Willensbekundung, für Aberglauben keinen Anlass geben und notwendigenfalls bessernd eingreifen zu wollen, ${ }^{61}$ legte dem immerhin gewisse Einschränkungen auf, ohne aber konkret zu werden. Die beiden handfesten Konzessionen an die Lutheraner waren die Gewährung der Priesterehe für bereits verheiratete Geistliche, doch der, so kain ebeweib nimbt und wharbafftige keuschbait hellt, besser thue, und die Zulassung des Laienkelchs - beides aber auch nur, bis ein Konzil darüber entscheiden möge. ${ }^{62}$

Im Ganzen ist das Augsburger Interim als katholisch zu charakterisieren, auch wenn es einen äußerst gemäßigten Ausdruck vorwies und auf schädliche Polemik verzichtete. Seine nicht immer eindeutigen Bestimmungen verlangten den Protestanten viel ab. Doch Widerstand formierte sich vorwiegend auf altgläubiger Seite. Weil dem concili furgegriffen, würde der Kaiser seine Kompetenzen überschreiten. ${ }^{63}$ Äußerst widerwillig stimmte Karl V. einer Geltungsbeschränkung auf die Protestanten zu. ${ }^{64}$ Damit blieb die angestrebte Reunion unverwirklicht, und es konnte nur noch darum gehen, die Protestanten zur Annäherung an die Papstkirche zu bewegen.

56 Mehlhausen, Das Augsburger Interim (wie Anm. 43), S. 108.

57 Ebd., S. 120.

58 Moritz, Interim und Apokalypse (wie Anm. 4), S. 125.

$59 \mathrm{Vgl}$. in dieser Einschätzung LeOpold von Ranke, Deutsche Geschichte im Zeitalter der Reformation, Nachdruck der von Prof. Dr. Paul Joachimsen hist.-krit. hrsg. Ausg., Bd. 5, Buch 9, Merseburg/Leipzig 1933, S. 26.

60 Vgl. Mehlhausen, Das Augsburger Interim (wie Anm. 43), S. 134-145. - Zu den Gebräuchen im Augsburger Interim vgl. ausführlich SowADE, Das Augsburger Interim (wie Anm. 48), S. 296-372.

61 Vgl. Mehlhausen, Das Augsburger Interim (wie Anm. 43), S. 136-138, 144.

62 Vgl. ebd., S. 142.

63 Vgl. RTA J.R. 18.2, Nr. 186, S. 1778-1783: Bedenken der katholischen Fürsten zur Märzfassung des Interims, Augsburg, vor dem 7. April 1548.

64 Vgl. dazu die Vorrede des Augsburger Interims: Mehlhausen, Das Augsburger Interim (wie Anm. 43), S. 34. 
Wurden viele protestantische Fürsten für das Religionsgesetz gewonnen, ${ }^{65}$ sperrte sich neben Johann von Küstrin, dem Herrn der Neumark, ${ }^{66}$ auch Moritz von Sachsen vehement. In der zweiten Märzhälfte des Jahres 1548 suchten die Kurbrandenburger und Kurpfälzer uff der ksl. und kgl. Mtt. befelb die Bedenken von Moritz zu zerstreuen. Doch jener blieb aufgrund der ihm und seinen Ständen dereinst gegebenen Zusagen bei seiner distanzierten Haltung, das diese sache seiner $k f l$. Gn. seble, ebre und gewissen und dorzu derselben underthane mit betreffe. Dorinne wusten sich sein kfl. Gn. sampt denen, die er bei sich het, allein nichts zcu entschliessen. Es stunde auch bei seiner $k f l$. Gn. nicht, hierin etwas zu willigen ane rath irer gelerten in der hl. schrieft und abne bewilligunge irer landtschaft. ${ }^{67}$ Dagegen warnten die anderen beiden Kurfürsten, im Falle der Nichtannahme wurde es im $\mathrm{bl}$. Reiche eine zerruttunge machen, dann das interim wurde durchaus gehen und von allen stenden gehalten werden. ${ }^{68}$ Des Weiteren ergänzten sie diese klar politische Argumentation durch die Warnung, dem sächsischen Kurfürsten könnte kaiserliches Ungemach drohen. Eine Unterredung mit dem Reichsoberhaupt am 24. März verlief ebenso ergebnislos. Erst Ferdinand, mit dem Moritz freundschaftlich verbunden war, konnte ihm immerhin das Zugeständnis abnötigen, was alle andere Kff., Ff. und stende schlössen, das sein kfl. Gn. dasselbige wieder endern noch wenden konten. ${ }^{69}$ Mit dieser Erklärung, trotz mangelnder Zustimmung der kursächsischen Landstände keine Schwierigkeiten auf Reichsebene zu bereiten, zeigte sich Karl V. zufrieden und interpretierte sie als persönliche Unterwerfung des Kurfürsten.

65 Vgl. Luttenberger, Glaubenseinheit und Reichsfriede (wie Anm. 7), S. 465; Rabe, Reichsbund und Interim (wie Anm. 34), S. 432 f.; Ranke, Deutsche Geschichte im Zeitalter der Reformation, Bd. 5, Buch 9 (wie Anm. 59), S. 28.

66 Vgl. Kawerau, Johann Agricolas Antheil (wie Anm. 37), S. 425-429; C. Zitelmann, Die Verhandlungen des Markgrafen Johann von Küstrin mit König Ferdinand und Kaiser Karl V. wegen Annahme des Interims. Gepflogen auf dem Reichstage zu Augsburg im Jahre 1548. Zeitgenössischer Bericht, in: Zeitschrift für Preußische Geschichte und Landeskunde 4 (1867), S. 73-84, 151-164, 412-426, hier S. 73-84; PKMS 3, Nr. 1038, S. 762 f.: Mgf. Hans von Küstrin an Kg. Ferdinand, Augsburg, 26. März 1548; RTA J.R. 18.2, Nr. 182, S. 1751-1768: Partikularverhandlungen mit Mgf. Johann von Brandenburg-Küstrin über die Annahme der Märzfassung des Interims, Augsburg, 21.-28. März 1548; ebd., Nr. 183, S. 1768 f.: Stellungnahme Mgf. Johanns von Brandenburg-Küstrin gegenüber Kg. Ferdinand zur Märzfassung des Interims, Augsburg, 26. März 1548.

67 RTA J.R. 18.2, Nr. 181, S. 1743-1751: Partikularverhandlungen mit Kf. Moritz von Sachsen über eine Annahme der Märzfassung des Interims, Augsburg, 17.-24. März 1548, hier S. 1743; siehe die Originalabschrift: Sächsisches Staatsarchiv - Hauptstaatsarchiv Dresden (im Folgenden: HStA Dresden), 10024 Geheimer Rat, Loc. 10297/22. Das sogenannte Interim, worüber Kurpfalz und Braunschweig [sic!; Kurbrandenburg, F. E.] mit Kursachsen Rat gepflogen, März 1548; als Regest: PKMS 3, Nr. 1030, S. 755758: Protokoll über die Interimsverhandlungen mit Kf. Moritz, Augsburg, 17.-24. März und 15. Mai 1548. - Vgl. weiterhin Issleib, Moritz von Sachsen 1547-1548 (wie Anm. 24), S. 207-213.

68 RTA J.R. 18.2, Nr. 181, S. 1744.

69 Ebd., S. 1751. 
Obzwar der Kaiser dem Sachsen die Heimreise verwehrte, ${ }^{70}$ wohl um ihn vom Einfluss seiner Theologen fernzuhalten - nicht zuletzt waren gegen Philipp Melanchthon wegen seiner publizistischen Beteiligung am Schmalkaldischen Krieg kaiserliche Drohungen ausgesprochen worden ${ }^{71}$-, veranlasste Moritz die Erstellung mehrerer Gutachten, um sich guten Gewissens in der Interimsangelegenheit positionieren zu können. Den Auftakt stellte eine Zusammenkunft des kursächsischen Rates Georg von Komerstadt und Melanchthons am 30. März in Altzella dar. Der Gelehrte verfasste am nächsten Tag nach Sichtung des Interimstextes ein erstes Gutachten ${ }^{72}$ und setzte auf Veranlassung Komerstadts ein etwas ausführlicheres zweites auf, welches dann an den in Augsburg weilenden Kurfürsten gesandt wurde. Schon hier steckte Melanchthon seine auch für später charakteristische Grundhaltung ab: Man müsse für das Seelenheil Nötiges von Unnötigem trennen, solle über Kleinigkeiten nicht streiten und Friedfertigkeit an den Tag legen. Einigkeit tue not, doch etliche Interimsartikel seien unrecht. ${ }^{73}$ In einem Begleitschreiben berichtete Komerstadt an Moritz von der Angst Melanchthons vor innerer Unruhe und Krieg mit dem Kaiser. Was man nachgeben könne, solle nach des Theologen Meinung geschehen. Alles andere müsse auf einem Konzil zur Disposition gestellt werden. ${ }^{74}$ Die Gefahr der Spaltung innerhalb der Lutheraner durch das Interim und die Verfolgung der Standhaften trieb Melanchthon weiterhin um: Dazu will ich aber nicht belfen, und will viel lieber sterben. ${ }^{75}$

Vom 19. bis zum 24. April kamen neben Melanchthon noch Georg Major, Caspar Cruziger und Johannes Pfeffinger sowie einige weltliche Räte abermals in Altzella zusammen, um über das Interim zu beraten und ein noch umfangreicheres Gutachten zu verfassen. Unter den Stücken rechter Lehre sei viel Betrug gemengt - so insbesondere in der doppelten Rechtfertigungslehre. Scharfe Kritik äußerten sie an Heiligenanrufung, Privat- und Seelenmessen. Dafür erboten sie sich, die kirchliche Hierarchie und die Zeremonien anzuerkennen. ${ }^{76}$ Auch der wenige Tage später von Melanchthon an Georg von Carlowitz geschriebene, von Komerstadt lancierte und für den Kaiser gedachte Brief offenbart die tiefe Friedfertigkeit Melanchthons, die er selbst der Streitlust Luthers, unter der der feinfühlige Theologe viel gelitten hätte, gegenüberstellte. Verständnis ist Melanchthon für diesen

70 Vgl. ebd.

71 Vgl. ebd., S. 1745 f., 1749 f.

72 Vgl. CR 6, Nr. 4189, S. 839-842 = MBW, Nr. 5105: Gutachten Melanchthons an Georg von Komerstadt, Altzella, 31. März 1548.

73 Vgl. CR 6, Nr. 4190, S. 842-845 = PKMS 3, Nr. 1040, S. 764-766 = MBW, Nr. 5110: Gutachten Melanchthons an Georg von Komerstadt für Kf. Moritz von Sachsen, Altzella, 1. April 1548.

74 Vgl. PKMS 3, Nr. 1045, S. 770 = MBW, Nr. 5112: Aufzeichnungen Komerstadts über mündliche Äußerungen Melanchthons für Kurfürst Moritz, Altzella, 1./2. April 1548.

75 CR 6, Nr. 4201, S. 853-855: Iudicium II. de libro Interim, 13. April 1548, hier S. 855; auch in PKMS 3, Nr. 1057, S. 777 f. = MBW, Nr. 5117.

76 Vgl. CR 6, Nr. 4212, S. 865-874: Iudicium III. de libro Interim, Altzella, 24. April 1548 $=$ PKMS 3, Nr. 1070, S. 788-790 = MBW, Nr. 5130. 
Schritt kaum entgegengebracht worden; nicht selten wurde er als nachträglicher Verrat an Luther gebrandmarkt. ${ }^{77}$ Doch offensichtlich stehen all die kursächsischen Positionierungen in einer Kontinuitätslinie, die darauf abzielte, den Spagat zwischen Dienstbarkeit gegenüber dem Kaiser und Glaubensfestigkeit zu wagen: Eine Religionseinheit wurde als erstrebenswert erachtet, dagegen galt der vom Kaiser eingeschlagene Weg in dieser Form als ungangbar.

Obwohl die Ausgangslage nicht sehr eindeutig war und eine Zustimmung aller Reichsstände nicht ohne Weiteres vorausgesetzt werden konnte, hatten sich diese am 15. Mai 1548 in der kaiserlichen Wohnung einzufinden, wo ihnen die Interimsvorrede $^{78}$ verlesen und die Annahme des Reichsreligionsgesetzes angetragen wurde. Der Verfahrensablauf dafür war dann etwas undurchsichtig: Die Kurien berieten ungefähr eine Stunde, der mit der einseitigen Stoßrichtung gegen die Protestanten unzufriedene Moritz von Sachsen wurde im Kurfürstenrat überstimmt, und Sebastian, der Kurfürst von Mainz und Erzkanzler des Reiches, vermeldete Karl V. den Gehorsam aller Stände und bat dafür um Abschrift des Textes. ${ }^{79}$ Sämtliche oppositionelle Haltungen waren auf diese Weise verschwiegen worden. Indem der Kaiser seinerseits den Ständen Dank aussprach und die Versammlung aufhob, galt das Interim als beschlossen. Tags darauf wurde es in den Kurien verlesen und ohne weitere Beratung oder gutachterliche Stellungnahme vervielfältigt. ${ }^{80} \mathrm{Ob}$ die uneingeschränkte Gehorsamsbekundung durch den Mainzer Erzbischof ein vom Kaiser vorbereiteter Schachzug gewesen ist, mag strittig sein ${ }^{81}$ immerhin kam sie ihm sehr zupass.

77 Vgl. MBW, Nr. 5139: Brief Melanchthons an Christoph von Carlowitz, Altzella, 25. April $1548=$ CR 6, Nr. 4217, S. 879-885. - Siehe zudem die ausführliche Einordnung und Analyse des Briefs sowie dessen präzise zeitliche Datierung bei Heinz Scheible, Melanchthons Brief an Carlowitz, in: Gerhard May/Rolf Decot (Hg.), Melanchthon und die Reformation. Forschungsbeiträge (Veröffentlichungen des Instituts für Europäische Geschichte Mainz. Abteilung für Abendländische Religionsgeschichte, Beiheft 41), Mainz 1996, S. 304-332; Timothy J. Wengert, „Not by Nature Philoneikos“. Philipp Melanchthon's Initial Reactions to the Augsburg Interim, in: Dingel/Wartenberg, Politik und Bekenntnis (wie Anm. 4), S. 33-49.

78 Vgl. RTA J.R. 18.2, Nr. 191, S. 1799-1802: Proposition des Interims, Augsburg, 15. Mai 1548.

79 Vgl. ebd., Nr. 192, S. 1802: Erklärung der Annahme des Interims durch die Reichsstände, Augsburg, 15. Mai 1548.

80 Vgl. IssLeib, Moritz von Sachsen 1547-1548 (wie Anm. 24), S. 217 f.; Moritz, Interim und Apokalypse (wie Anm. 4), S. 119 f.; Rabe, Reichsbund und Interim (wie Anm. 34), S. 441-444; Ders., Zur Entstehung des Augsburger Interims (wie Anm. 35), S. 84-89; Ranke, Deutsche Geschichte im Zeitalter der Reformation, Bd. 5, Buch 9 (wie Anm. 59), S. 30 f. - Siehe die Schilderung des Annahmevorgangs in HStA Dresden, 10024 Geheimer Rat, Loc. 10297/22, fol. 12 ${ }^{\mathrm{r}}-13^{\mathrm{v}}=$ PKMS 3, Nr. 1030, S. 758 (Regest).

81 So geht Rabe davon aus, dass der Kaiser von der Zustimmung aller Stände äußerst überrascht gewesen sei und der Erzkanzler auf eigene Faust gehandelt hätte. Vgl. Rabe, Reichsbund und Interim (wie Anm. 34), S. 442 f.; Ders., Zur Entstehung des Augsburger Interims (wie Anm. 35), S. 87-89. 
Angesichts dessen ist es verständlich, dass die übergangenen protestantischen Stände diese Verfahrensweise nicht unkommentiert ließen. Einem Protest der überwiegend evangelischen Reichsstädte vom 19. Mai konnte Karl V. entgegenwirken, indem er mit ihnen zeitig Verhandlungen aufnahm, die zuweilen von militärischen Gewaltandrohungen gewürzt waren. ${ }^{82}$ Aber auch gegenüber den Territorialherren suchte er die vom Erzkanzler verkündete Annahme des Interims durch die viel erprobten Einzelverhandlungen $\mathrm{zu}$ sichern. ${ }^{83}$ Insbesondere bei Moritz von Sachsen und Johann von Küstrin war wenig zu erreichen. Konnte dem Sachsen, der die einseitige Belastung der Protestanten als wenig friedensstiftend kritisiert hatte, abgerungen werden, sich für seine Person mit dem Kaiser vergleichen und seinen Landständen die Billigung der Interimsartikel anraten zu wollen, ${ }^{84}$ musste der Markgraf unverrichteter Dinge in die Heimat entlassen werden. ${ }^{85}$ Ausgerechnet die beiden für die Außendarstellung im vorigen Krieg wichtigsten Verbündeten von Kaiser und König hatten sich in der Religionsfrage zunächst also am widerspenstigsten gebärdet.

\section{Melanchthon und die Adiaphora. Friedfertigkeit und Bekenntnispflicht}

Obwohl mit einem speziellen Zensuredikt jede Polemik gegen das Augsburger Interim verboten wurde, ${ }^{86}$ reagierten viele protestantische Theologen zeitnah mit einer Flut von Druckschriften auf das Religionsgesetz. Die erste war - unfreiwillig - ein Gutachten Philipp Melanchthons wohl zur Vorbereitung des für den 1. Juli 1548 einberufenen kursächsischen Landtags zu Meißen, ${ }^{87}$ das in Tradition zu seinen vorigen Stellungnahmen $\mathrm{zu}$ sehen ist. Sie alle hatte Kurfürst Moritz

82 Vgl. v. a. RTA J.R. 18.2, Nr. 202-208, S. 1855-1907.

83 Vgl. Rabe, Reichsbund und Interim (wie Anm. 34), S. 444-446; Ders., Zur Entstehung des Augsburger Interims (wie Anm. 35), S. 92-98.

84 Vgl. IssLeib, Moritz von Sachsen 1547-1548 (wie Anm. 24), S. 218 f.; RTA J.R. 18.2, Nr. 193a,b-194a,b, S. 1803-1812 = PKMS 3, Nr. 1097, 1100, 1105 f., S. 854-860.

85 Vgl. RTA J.R. 18.2, Nr. 195-198, S. 1812-1849; Zitelmann, Die Verhandlungen des Markgrafen Johann von Küstrin (wie Anm. 66), S. 151-164, 412-426.

86 Vgl. GStA PK, I. HA, Rep. 13 Religionsstreitigkeiten im Reich, Nr. 5a2 Das Interim, Fasz. 1 Das Interim, fol. 62: Zensuredikt vom 30. Juni 1548. Vgl. auch Mehlhausen, Das Augsburger Interim (wie Anm. 43), S. 34.

87 Vgl. Philipp Melanchthon, Bedencken auffs INTERIM Des Ehrwirdigen vnd Hochgelarten Herrn PHILIPPI MELANCHTHONIS (1548), bearb. von Hans-Otto Schneider, in: Irene Dingel (Hg.), Reaktionen auf das Augsburger Interim. Der Interimistische Streit (1548-1549) (Controversia et Confessio 1), Göttingen 2010, S. 4075. Dazu liegt auch ein Originaldruck vor: DeRs, Bedencken auffs INTERIM der Theologen zu Wittenberg, Magdeburg 1548 (VD 16: M 4322) = CR 6, Nr. 4259, S. 924942 = MBW, Nr. 5182 = PKMS 4, Nr. 14, S. 54-60. - Vgl. des Weiteren IssLeIb, Das Interim in Sachsen (wie Anm. 6), S. 194. - Laut Wartenberg, Philipp Melanchthon (wie Anm. 9), S. 71 wurde Melanchthon am 9. Juni in Leipzig die Erstellung des Gutachtens aufgegeben. 
angefordert, ${ }^{88}$ sodass der Gelehrte ,in ein bestimmtes politisches Programm eingespannt" war, das ihm die freie Meinungsäußerung nicht erlaubte. Zudem musste der etwas ängstliche Melanchthon Vorsicht walten lassen, zählte er doch „beim Kaiser zu den bestgehaßten Männern unter den Wittenberger Theologen".89 Es entsprach aber auch sicher seiner Natur, dass in dem auf den 16. Juni datierten und zusätzlich von Johannes Bugenhagen, Johannes Pfeffinger, Caspar Cruziger, Georg Major und Sebastian Fröschel 90 unterschriebenen Gutachten ein ausgesprochenes Bemühen um Mäßigung erkennbar ist. Das kann jedoch nicht über die ablehnende Grundhaltung der Theologen hinwegtäuschen. Besondere Brisanz erhielt das Gutachten erst deshalb, weil es vom noch in Wittenberg lehrenden Hebraisten und Theologen Matthias Flacius und dem Eislebener Stadtpfarrer Andreas Kegel ab Mitte Juli 1548 in den Magdeburger Druck lanciert wurde, um ihre Position mit Autoritäten zu untermauern und den abwägenden Melanchthon zum Farbe Bekennen für ein reines und unverfälschtes Luthertum zu bewegen. Mehrere Ausgaben erschienen, die eine weite Verbreitung erfuhren. ${ }^{91}$ Daraus erwuchsen Schwierigkeiten für Melanchthon, der sich vor Moritz zu einer Rechtfertigung gezwungen sah und jegliches eigene Dazutun zur Drucklegung abstritt.92 Aber schon Melanchthon und seine Mitarbeiter hatten ihr Gutachten abschriftlich stark verbreiten lassen, ${ }^{93}$ sodass eine Publizierung in diesen konfessionell aufgewühlten Zeiten nur folgerichtig scheint. Gleichwohl nahm Moritz seinen Theologen abermals gegen königliche und kaiserliche Anwürfe in Schutz, als ihre Hoheiten Landesverweis und Auslieferung forderten. ${ }^{94}$

Die Verfasser verwahrten sich in ihrem Gutachten gegen die Unterstellung, aus eygnem freuel, furwitz oder stoltz zu streiten. Man sehe sich aber zur bekentnis

88 Vgl. Irene Dingel, „Der rechten lehr zuwider“. Die Beurteilung des Interims in ausgewählten theologischen Reaktionen, in: Schorn-Schütte, Das Interim 1548/50 (wie Anm. 2), S. 292-311, hier S. 296 f.; Melanchthon, Bedencken auffs INTERIM, bearb. von Schneider (wie Anm. 87), S. 43.

89 Reichert, Amsdorff und das Interim (wie Anm. 9), S. 95.

90 Zur Verfasserschaft vgl. z. B. die Unterschriften bei CR 6, Nr. 4259, S. 942.

91 Siehe auch die englischen (London) und niederdeutschen (Lübeck) Ausgaben bei Melanchthon, Bedencken auffs INTERIM, bearb. von Schneider (wie Anm. 87), S. 54-57. - Vgl. weiterhin ebd., S. 44; Dingel, „Der rechten lehr zuwider“ (wie Anm. 88), S. 298; ReICHeRt, Amsdorff und das Interim (wie Anm. 9), S. 91.

92 Vgl. MBW, Nr. 5280: Brief Melanchthons an Kurfürst Moritz, Wittenberg, 3. September 1548; Nr. 5285: Brief Melanchthons an Kurfürst Moritz, Wittenberg, 8. September 1548 = PKMS 4, Nr. 89, S. 131.

93 Vgl. Dingel, „Der rechten lehr zuwider“ (wie Anm. 88), S. 298; Melanchthon, Bedencken auffs INTERIM, bearb. von Schneider (wie Anm. 87), S. 44; Kaufmann, Das Ende der Reformation (wie Anm. 4), S. 81, Anm. 143; Scheible, Melanchthon. Eine Biographie (wie Anm. 9), S. 191.

94 Vgl. PKMS 4, Nr. 81, S. 126: Ks. Karl V. an Kf. Moritz, Speyer, 31. August $1548=$ CR 7, Nr. 4340, S. 126-128; PKMS 4, Nr. 98, S. 142-144: Instruktion für Melchior von Ossa und Hans von Schönberg von Kf. Moritz an Kg. Ferdinand, 18. September 1548, hier S. 142; Nr. 145, S. 189: Kf. Moritz an Ks. Karl V., Torgau, 31. Oktober 1548. 
der rechten lebr gezwungen, auch wenn persönliches Unglück drohe. ${ }^{95}$ Obwohl dem Interim keine heilsame Wirkung zugesprochen werden könne - immerhin bliebe ja durch die bischöfliche Weigerung, in Lehre und Zeremonien Änderungen vorzunehmen, die Uneinigkeit im Reich bestehen - wollten sie unvoreingenommen urteilen. Es sollte sich zeigen, dass eine Willensbekundung für ihre folgenden theologischen Beratungen programmatischen Charakter bekam: [U]nd was recht ist, das wollen wir nicht Calumniose und Sophistice anfechten, sondern klar wnd einfeltig bekennen; dagegen was vnrecht ist, das sollen wir nicht billichen. ${ }^{96}$

An der doppelten Rechtfertigungslehre wurde dann herbe Kritik geübt, da der Liebe und der eingegossenen Gerechtigkeit ein zu großer Stellenwert beigemessen worden wäre. Schon Luther hatte sich gegen solche Überlegungen des Regensburger Religionsgesprächs von 1541 gestellt. ${ }^{97}$ Vor Gott könne man allein gerecht werden vmb des Heylands Christi willen, durch das vertrawen auff $j$ bn ond nicht von wegen vnser reynigkeit. ${ }^{98}$ Die komplizierte Rechtfertigungslehre des Interims wurde auch eindeutig verworfen: Vnd so mans gleich subtil entschuldiget ond die stücklin hin wnd her zusamenliset, so ist es jm doch selb wiederwertig. ${ }^{99}$ Dementsprechend lehnten die kursächsischen Theologen die Lehre vom Messopfer ab, da bei jener das menschliche und nicht das göttliche Wirken beim Erlangen der Seligkeit auf unzulässige Weise in den Vordergrund gerückt werde. Weiterhin wurde partiell Widerspruch gegen die sieben Sakramente sowie die Seelen- und Privatmessen geäußert ${ }^{100}$ und die Heiligenanrufung als unzumutbar dargestellt, denn allein Jesus sei der mitler, versöner vnd fürbitter ${ }^{101}$ vor Gott.

Trotz inhaltlicher Differenzen signalisierte Melanchthon seine Bereitschaft, die Hierarchie der alten Kirche mit ihren Bischöfen anzuerkennen, wenn sie die warbeit nicht verfolgen wnd nicht abgöttische Ceremonien jm Landt widerumb auffrichten. ${ }^{102}$ Noch am 29. April hatte Melanchthon an Moritz geschrieben: Man siehet offentlich, daß vergebens ist mit den Verfolgern Vergleichung zu machen, und so man gleich daran flicken will, so ist es ein Friede wie zwischen Wölfen und Schaafen. ${ }^{103}$ Das kurzzeitige Umdenken in Bezug auf die Kirchenhierarchie reichte aber nicht so weit, dem Konzil die ausschließliche Bibelexegese zuzu-

\footnotetext{
95 Vgl. Melanchthon, Bedencken auffs INTERIM, bearb. von Schneider (wie Anm. 87), hier S. 59.

96 Ebd., S. 60.

97 Vgl. Dingel, „Der rechten lehr zuwider“ (wie Anm. 88), S. 298 f.

98 Melanchthon, Bedencken auffs INTERIM, bearb. von Schneider (wie Anm. 87), S. 61.

99 Ebd., S. 63.

100 Vgl. ebd., S. 65-70.

101 Ebd., S. 71.

102 Ebd., S. 65.

103 CR 6, Nr. 4220, S. 888-890: Iudicium de restituenda Episcopis Iurisdictione etc., hier S. $889=$ PKMS 3, Nr. 1077, S. $797=$ MBW, Nr. 5141.
} 
billigen, da man nicht wie in weltlichen Königkreichen einer gewissen person gewaldt geben könne, deutunge zu machen jres gefallens. ${ }^{104}$

Kompromissbereitschaft zeigte Melanchthon Mitte Juni dann aber in den Adiaphora, wenn die Kernstücke evangelischer Lehre dabei nicht beeinträchtigt würden. Um Einigkeit und Kirchenzucht aufrechtzuerhalten, könnten gewisse Zeremonien durchaus zugelassen werden, denn wir wollen von denselben mitteldingen nichts zancken, souil den Christlichen brauch belanget. 105

Das Konzept der ,Mitteldinge' reicht bis in die antike Philosophie zurück, nach der ein Adiaphoron das ethisch Gleichgültige sei, das zwischen Gut und Böse stehend weder zu Glückseligkeit noch Unheil beitrage. Bezogen auf die christliche Ethik des Mittelalters war ein Adiaphoron eine durch Gott weder verbotene noch gebotene Handlung. Auch Luther diskutierte ab 1530 den Begriff und das damit verbundene Problem mit Melanchthon und urteilte, dass alle solche eusserliche weise anzunemen sind umb friede willen, so fern ihm sein gewissen damit nicht beschweret werde. ${ }^{106}$ In diesen Adiaphora fanden sich die Gutachter also auch bei den Beratungen über das Interim zu Zugeständnissen bereit.

Anfang April 1548 hatte Melanchthon die Wiedereinführung altkirchlicher Zeremonien noch verurteilt, denn sonderlich solche äußerliche Ceremonien, die vor Augen sind, bewegen das gemeine Volk heftiger denn andere Sachen, die nicht also vor Augen sind. ${ }^{107}$ Dessen waren sich die Theologen wohl bewusst, als sie Mitte Juni die Adiaphora als Kompromissgegenstand offerierten. Dies ist auch keineswegs als Kurswechsel zu werten, sondern eher konsequent, da sie ein besonderes Augenmerk darauf legten, welche Zeremonien als Mitteldinge zu gelten hätten, damit sie dem reinen Glauben keinen Abbruch täten. Nun rieten die Theologen, dass man die lehr von vnterscheidt rechtem Gottestdienst vnd solchen mitlen, vnnötigen dingen nicht verleschen lassen dürfe. ${ }^{108}$ Adiaphora hätten also keinesfalls als heilsnotwendig zu gelten.

Schließlich könne die als wahr erkannte Lehre - anders als vielleicht so manche Zeremonie - unter keinen Umständen aufgrund politischen Drucks geändert werden, denn keine Creatur Göttliche warheit zu endern macht hat. Obwohl sie wüssten, dass ein Wirken gegen das Interim verboten sei, dürfe kein anderes Urteil gefällt werden: Dieweil das Interim in vielen Artickeln, die wir angezeiget haben, der rechten lehr zuwider ist, so müssen wir danon warhafftige bericht vnd warnung thun. 109

104 Melanchthon, Bedencken auffs INTERIM, bearb. von Schneider (wie Anm. 87), S. 65.

105 Ebd., S. 72. - Im Originaldruck VD 16: M 4322 (wie Anm. 87), fol. Dr heißt es sogar noch expliziter: souiel den eusserlichen brauch belanget.

106 Vgl. und zit. nach Mehlhausen, Der Streit um die Adiaphora (wie Anm. 7), hier S. $105 \mathrm{f}$.

107 CR 6, Nr. 4190, S. 842-845, hier S. 843.

108 Melanchthon, Bedencken auffs INTERIM, bearb. von Schneider (wie Anm. 87), S. 72.

109 Ebd., S. 74. 
Am 2. Juli legte Moritz von Sachsen den ständischen Vertretern auf dem Landtag zu Meißen die bisherige Entwicklung in der Religionsfrage dar und bat sie, solche Kaiserliche Ordnung zu beratschlagen und zu beantworten, damit die Kais. Maj. vermerken können, daß wir und ibr geneigt sind, uns in allem, was zu christlicher Vergleichung, Rube, Friede und Einigkeit dienstlich, und mit Gott und gutem Gewissen geschehen kann, unterthänigst gehorsamst zu verhalten. ${ }^{110}$

Die Ständevertreter lehnten am 3. Juli das Interim einhellig ab ${ }^{111}$ und die anwesenden Theologen ${ }^{112}$ machten sich umgehend ans Werk. Sie erstellten ein weiteres, äußerst umfangreiches Gutachten.113 In der Vorrede kritisierten sie, dass dem Konzil vorgegriffen werde, die schon in Trient getroffenen Konzilsbeschlüsse, denen man sich laut Interim unterwerfen solle, jenem teilweise widersprächen und die Gegenseite allein für sich das Attribut ,katholisch' deklariere, obwohl doch gerade deren Glaubenspraxis von Missbräuchen durchsetzt sei. ${ }^{114}$ An ihrer Ablehnung der duplex iustificatio hielten sie fest und führten ihre Meinung dazu weiter aus, um alle Unklarheiten über ihren Standpunkt zu beseitigen. ${ }^{115}$ Nun richteten sich die Theologen aber auch gegen die Kirchenhierarchie, die man ja zuvor noch bereit gewesen war, zu akzeptieren. Das wäre der hässigste Artickel [...]; denn da ist ibr, der katholischen Bischöfe, nervus, daran ist ibnen allein gelegen. ${ }^{116} \mathrm{Oft}$ habe man sich erboten, die Bischöfe mit ihren Rechten und Besitzungen anzuerkennen, wenn sie die Evangelischen bei ihrem Glauben lassen und nicht unterdrücken würden. Es wäre aber ersichtlich, wie jene in der eingeräumten Jurisdiction handeln sollen, mit Aufrichtung aller Abgötterey, auch Verjagung der frommen Priester, so die blasphemische Abjuration nicht thun. Bevor die Jurisdiktion der Bischöfe nicht einer Reformation unterzogen werde, könne sie also nicht akzeptiert werden, denn in der Jurisdiction würden sie auch ibren vorigen bösen Gebräuchen nachgehen. 117 Je mehr Zeit verstrich, um über die Bestimmungen des Interims nachzudenken, desto radikaler und ablehnender äußerten sich Melanch-

110 CR 7, Nr. 4279, S. 5-7: Mauritius Elector ad Ordines Misn., hier S. 7 = PKMS 4, Nr. 33, S. 73 f., hier S. 74. - Im Grunde handelte es sich eher um einen Landesausschusstag.

$111 \mathrm{Vgl}$. u. a. MBW, Nr. 5201: Brief Melanchthons an Erasmus Benedikt, Meißen, 4. Juli $1548=$ CR 7, Nr. 4282, S. 10; MBW, Nr. 5202: Brief Melanchthons an Paul Eber, Meißen, 4. Juli $1548=$ CR 7, Nr. 4283, S. 10 f.

112 Das waren Fürst Georg von Anhalt, Philipp Melanchthon, Caspar Cruziger, Johannes Pfeffinger, Daniel Greser (Greiser/Gresser), Georg Major und Johann Forster. Die personelle Kontinuität ist nicht zu verkennen. Vgl. CR 7, Nr. 4286, S. 12-45: Iudicium V. de libro Interim, Meißen, 6. Juli 1548, hier S. 45 = MBW, Nr. 5208 = PKMS 4, Nr. 34, S. 74-84, hier S. 84, Anm. 1.

113 Zuweilen wird jenes mit dem Gutachten vom 16. Juni verwechselt oder gar für ein und dasselbe gehalten. Vgl. Gehrt, Ernestinische Konfessionspolitik (wie Anm. 11), S. 44 f.; Reichert, Amsdorff und das Interim (wie Anm. 9), S. 98, Anm. 7.

114 Vgl. CR 7, Nr. 4286, S. 12-45, hier S. 13-16.

115 Vgl ebd., S. 16-24.

116 Ebd., S. 25.

117 Ebd., S. 28. 
thon und seine Kollegen, sodass dies auf dem Landtag zu Meißen in eine „Fundamentalkritik“118 mündete.

Allein in den Adiaphora fanden sich die Theologen wieder zu Zugeständnissen bereit. Tatsächlich wurde hierfür das Gutachten vom 16. Juni streckenweise direkt übernommen. ${ }^{119}$ Viele Zeremonien, die zu Aberglaube Anlass geben könnten, wie Privat- und Seelenmessen, Heiligendienst und Prozessionen seien weiterhin abzulehnen. ${ }^{120}$ Doch liturgische Kleidung für Priester, gewisse Gesänge, das Totengedenken oder auch der Festkalender dürften als Mitteldinge angenommen werden, da sie der Kirchenzucht dienlich seien. ${ }^{121}$ Die weltliche Obrigkeit könne auch Fastenregelungen beschließen, jedoch mit der Maß, daß kein cultus daraus gemacht, noch die Gewissen damit beschweret werden. ${ }^{122}$

Die Theologen trachteten aber nicht danach, den Landesvertretern ihre beständige Meinung aufzunötigen: Die Landschaft wolle selbs schließen, was sie aufs $\ddot{a} u$ ßerst und entlich halten wolle, und ibre Fährlichkeit selb bedenken. Verlangen könnten sie nichts und wollten so lange dienen, wie man sie dulde. ${ }^{123}$ Die Trennung von politischer und religiöser Domäne in der Gedankenwelt der Theologen, um dem Land und seinen Bewohnern zu gewährleisten, die Zeitläufte unbeschadet $\mathrm{zu}$ überstehen, ist schon sehr beachtlich. Melanchthon griff dies später in einem Brief an Johann von Küstrin wieder auf: Vnd ist jn summa ein leichte frage, was prediger ond Lebrer thun sollen, Wie aber den weltlichen Regenten zu radten sey, dises ist mancherley. ${ }^{124}$ Überhaupt gelte es für Politiker, überlegt zu handeln und nicht durch allzu offenen Bekenntniseifer auf sich aufmerksam zu machen. In so vielen Orten schien Widerstand wahrscheinlich, man möge die Angelegenheit daher lieber aussitzen. Es stünde zu hoffen, die Sach werde jn einen vertzug kbomen, Darumb ist mit der antwort an Karl V. nicht zu Eilen. ${ }^{125}$

Gemäß dieser Strategie rieten die Theologen den Ständevertretern, beim Kaiser um die Beibehaltung der geltenden sächsischen Kirchenverfassung anzusuchen, anstatt ihm die Gegenartikel zu präsentieren. ${ }^{126}$ Kurfürst Moritz hielt aber auch das für unklug und ließ sie den Brief an seine Person adressieren. ${ }^{127}$ Der Kaiser

118 JÜrgens, Flacius gegen Melanchthon (wie Anm. 7), S. 208.

119 Vgl. dafür CR 6, Nr. 4259, S. 939 f. mit CR 7, Nr. 4286, S. 40 f.

120 Vgl. CR 7, Nr. 4286, S. 38-43.

121 Vgl. ebd., S. 42 f.

122 Ebd., S. 44.

123 CR 7, Nr. 4287, S. 45: Ad ordines Misn., 6. Juli 1548.

124 GStA PK, I. HA, Rep. 13 Religionsstreitigkeiten im Reich, Nr. 5a2 Das Interim, Fasz. 1, fol. 65-67: Brief Melanchthons an Markgraf Johann von Küstrin, 31. Juli 1548, hier fol. $66^{\mathrm{r}}=$ CR 7, Nr. 4308, S. 84-87, hier S. 85 .

125 GStA PK, I. HA, Rep. 13, Nr. 5a2, Fasz. 1, fol. $66^{\mathrm{v}}=$ CR 7, Nr. 4308, S. 86.

126 Vgl. MBW, Nr. 5210: Die Theologen an die Landstände, Meißen, 6. Juli $1548=$ CR 7, Nr. 4291, S. 64 f.; MBW, Nr. 5211: Die kursächsischen Landstände an den Kaiser (Entwurf), Meißen, 6. Juli 1548 = PKMS 4, Nr. 38, S. 85 f.

127 Vgl. MBW, Nr. 5215: Die kursächsischen Landstände an Kf. Moritz von Sachsen, Meißen, 8. Juli $1548=$ CR 7, Nr. 4292, S. 65-68 = PKMS 4, Nr. 39, S. 86. - Vgl. außerdem PKMS 4, Nr. 38, S. 86, Anm. 1a. 
sollte aus den kursächsischen Disputationen anscheinend lieber herausgehalten werden.

Neben dem umfassenden Gutachten entstand durch die Feder Melanchthons noch ein weiteres, ${ }^{128}$ welche beide zusammen von Flacius wie jenes vom 16. Juni in den Magdeburger Druck gebracht wurden. ${ }^{129}$ Es entwickelte für zentrale Punkte, so für die Rechtfertigungslehre, positive Lehrgrundsätze und hatte daher das Augsburger Interim nicht mehr offen zum Gegenstand, an dem sich die Theologen abarbeiteten. Inhalt und Vorgehensweise waren beispielgebend für die folgenden Verhandlungen. ${ }^{130}$ Mit dem Meißener Landtag hatte sich die Gewissheit gebildet, dass Kursachsen das Interim nicht annehmen würde, jedoch zugleich die Konfrontation mit dem Kaiser scheute. Es konnte ab diesem Moment nur noch darum gehen, sich elegant aus der Affäre zu ziehen. Und so zeichnete sich schon der albertinische Sonderweg ab.

\section{Der sächsische Sonderweg nimmt Gestalt an. Die Treffen in Pegau, Torgau und Altzella}

Kurfürst Moritz von Sachsen und seine politischen Berater mussten auf diverse, sich teilweise bekämpfende Interessenparteien in der Interimsfrage Rücksicht nehmen. Seine Theologen hatten aus ihrer Ablehnung keinen Hehl gemacht, und die kursächsischen Stände waren ihrem Votum gefolgt. Dagegen drang Karl V. nach wie vor auf die vollständige Einführung seines Religionsgesetzes. Eine essenzielle Vorliebe pflegten dafür auch die altgläubigen Bischöfe von Meißen, Johann VIII. von Maltitz, und von Naumburg, Julius Pflug, der die Inhalte des Augsburger Interims immerhin maßgeblich zu verantworten hatte. Es lag auf der Hand, dass eine Übereinkunft nur durch weitere Gespräche zu erreichen sein würde.

Die nächsten Verhandlungen fanden vom 23. bis 25. August 1548 in Pegau statt. ${ }^{131}$ Moritz verfügte, dass der evangelische Bischof von Merseburg, Fürst Georg III. von Anhalt, den anwesenden Räten und Theologen ${ }^{132}$ Bericht erstatten

128 Vgl. MBW, Nr. 5209: Gutachten/Lehrformel für die kursächsischen Landstände, Meißen, 6. Juli $1548=$ CR 7, Nr. 4290, S. 48-64.

129 Vgl. Philipp Melanchthon, Bericht vom INTERIM der Theologen zu Meissen versamlet, Magdeburg 1548 (VD 16: B 1847).

130 Vgl. in dieser Einschätzung auch Reichert, Amsdorff und das Interim (wie Anm. 9), S. 99; Emil Friedberg, Agenda, wie es In des / Churfürsten zu Sachsen / Landen In den kirchen gehalten wirdt. Ein Beitrag zur Geschichte des Interim, Halle 1869, S. 3.

$131 \mathrm{Zu}$ den Verhandlungen in Pegau vgl. insbesondere IssLeib, Das Interim in Sachsen (wie Anm. 6), S. 201-205; Reichert, Amsdorff und das Interim (wie Anm. 9), S. 121-123; Waschiüsch, Alter Melanchthon (wie Anm. 7), S. 44-46.

132 Das waren die kursächsischen Räte Georg und Christoph von Carlowitz, Melchior von Ossa, Ludwig Fachs und Heinrich von Bünau sowie zusätzlich zu Georg von Anhalt die Theologen Philipp Melanchthon, Johann Forster und Paul Eber. Letzterer war für den erkrankten Caspar Cruziger eingesprungen. Vgl. u. a. Scheible, Melanchthon. Eine Biographie (wie Anm. 9), S. 193 f. 
sollte über seine Unterhandlungen mit seinem katholischen Kollegen aus Naumburg wegen des Interims. Danach solle mit Pflug und Maltitz über die unverglichenen Punkte verhandelt werden. Einerseits sei den katholischen Bischöfen zu verdeutlichen, dass sie sich mit dem Erhalt ihrer Jurisdiktion zufrieden geben und beim Kaiser um die Beibehaltung der hergebrachten kursächsischen Kirchenverfassung ansuchen mögen. ${ }^{133}$ Andererseits verlangte Moritz von den Theologen, sie wollten sich eines Theils halsstarriger Leute, die nicht viel zu verlieren haben, gar nicht bewegen noch auch etwas anfechten lassen, sondern rathen, daß in allen entwichen werde, das obne Verletzung der offentlichen heiligen göttlichen Schrift gescheben kann. ${ }^{134}$ Es sei fürderhin besser, in Nebensächlichkeiten nachzugeben, als dass durch einen Krieg endlich die ganze Religion [...] verdruckt und gedämpft möchte werden. ${ }^{135}$

Zwar verhandelte Georg von Anhalt mit Julius Pflug, doch erreichen konnte er hier zunächst nichts. ${ }^{136}$ Und auch die evangelischen Theologen lehnten aus bekannten Gründen mittels einer Aufzählung der Unzumutbarkeiten das Interim konsequent $\mathrm{ab},{ }^{137}$ wobei sie abermals in den Zeremonien ihr Entgegenkommen signalisierten. ${ }^{138}$ Dennoch konnten sich die Streitparteien in der Rechtfertigungslehre vergleichen. Am 24. August 1548 besprachen sich die katholischen Bischöfe mit den kurfürstlichen Räten und Theologen über den Entwurf Melanchthons, den er im Zuge der Meißener Versammlung erstellt hatte. Freilich waren Pflug und Maltitz höchst unzufrieden und wollten weitreichende Änderungen vorgenommen wissen, wogegen sich ihre evangelischen Widersacher vehement sperrten. Erst auf Zureden der Räte konnten letztere davon überzeugt werden, einen Kompromissvorschlag anzunehmen und in die ansonsten unveränderte Lehre ${ }^{139}$ einen Passus einzufügen, der die guten Werke als Folge - nicht als Voraussetzung - der Gerechtigkeit deklarierte: $[D]$ as der mensch durch den bei. geist ernewert vnd gerechtigkeit mit dem werg vorbringen kann und das goth Ihnen, diesen swachen angefangenen gehorsam, in dieser elenden gebrechlichen natur vmb seines sohns willen in den glauben wil gefallen lassen. ${ }^{140}$

133 Vgl. CR 7, Nr. 4328, S. 108-113: Mauritius ad legatos suos, 19. August 1548, hier S. 108$111=$ PKMS 4, Nr. 70, S. 110-112, hier S. 110 f.

134 CR 7, Nr. 4328, S. 112.

135 Ebd., S. 113.

136 Vgl. PKMS 4, Nr. 76, S. 123 f.: Bericht von Ludwig Fachs über die Pegauer Handlung an Kf. Moritz, Pegau, 25. August 1548, hier S. 123.

137 Vgl. ebd., Nr. 73, S. 113 f.: Bedenken von Georg von Anhalt, Philipp Melanchthon und Johann Forster zur Antwort an den Ks., den kfl. Räten übergeben, Pegau, 23. August 1548, hier S. $114=$ CR 7, Nr. 4332, S. 117-119= MBW, Nr. 5264.

138 Vgl. PKMS 4, Nr. 73, S. 113 f. = CR 7, Nr. 4331, S. 115-117 = MBW, Nr. 5265.

139 Vgl. PKMS 4, Nr. 74, S. 115-122: Der zwischen den kfl. Räten, Theologen und den Bf. von Naumburg und Meißen verglichene Rechtfertigungsartikel, Pegau, 24. August 1548 = MBW, Nr. 5268 .

140 PKMS 4, Nr. 75, S. 122 f.: Notiz zum Pegauer Rechtfertigungsartikel, Pegau, 24./25. August $1548=$ CR 7, Nr. 4334, S. 120-122, hier S. 121. 
Infolgedessen entspann sich ein Wortgefecht zwischen Melanchthon und den katholischen Bischöfen, ob jener Kompromiss nun den Bestimmungen des Augsburger Interims gemäß wäre. $\mathrm{Zu}$ dieser Erklärung wollte sich der Wittenberger Theologe keineswegs hinreißen lassen. Gerade die Räte waren über Melanchthons Halsstarrigkeit konsterniert, denn in der Folge verweigerten die Bischöfe alle weiteren Verhandlungen, da es nicht in ihrer Macht stünde, das Reichsgesetz zu ändern. Die Sachsen würden besser daran tun, das Interim einzuführen, damit ein Kriegszug verhindert werden könne. ${ }^{141}$ Das war ein ganz unverhohlener Rat der katholischen Würdenträger, in der Religion nachzugeben, um weltliche Weiterungen zu vermeiden. Aber wenigstens war eine Lösung in der Rechtfertigungslehre, dem Kernstück evangelischer Theologie, gefunden worden.

Die Ausarbeitung eines kursächsischen Religionsgesetzes blieb mitnichten eine innersächsische Angelegenheit. Joachim II., der selbst noch keine Anstalten zur Veränderung der Religion im eigenen Lande gemacht hatte, war von König Ferdinand der Auftrag erteilt worden, durch alle fueglich weeg vnnd mittl Kurfürst Moritz und Markgraf Johann dazu zu bringen, bemellte Religion ordnung zuerhalltung bestenndigs Frids vnnd ainigkait on lennger verziehen anzenemen, jn jren Landen Publiciern zelassen vnnd darob genntzlich onnd ernnstlich zehallten. ${ }^{142}$ Dafür müsste er mit bestem Beispiel vorangehen. Doch schon am 16. September hatte der kursächsische Rat Christoph von Carlowitz mit dem brandenburgischen Diplomaten Timotheus Jung während eines Treffens in Jüterbog vereinbart, in der Interimsfrage eine gemeinsame Linie zu suchen. Joachim war erfreut, dass Moritz seinen Widerstand scheinbar aufgeben wollte. ${ }^{143}$

Anlässlich der Hochzeitsfeierlichkeiten von Herzog August von Sachsen mit der dänischen Prinzessin Anna vom 7. bis 13. Oktober in Torgau redete nun der Brandenburger auf Moritz ein, das Interim anzunehmen. Der bat Joachim wiederum, ihm seine Bedenken schriftlich zukommen zu lassen. Dafür solle er darüber auf dem Laufenden gehalten werden, wozu sich die sächsischen Theologen und Räte entschließen würden. Es ist durchaus möglich, dass Moritz mit dieser Hinhaltetaktik zunächst ,Zeit schinden' wollte, denn zugleich vereinbarte er wohl auch wegen der Religion - mit Markgraf Johann, in ein geplantes Schutzbündnis mit dem König von Polen, Sigismund August, einzutreten. Dazu kam es dann aber nicht. ${ }^{144}$

141 Vgl. PKMS 4, Nr. 76, S. 123 f.

142 GStA PK, I. HA, Rep. 13 Religionsstreitigkeiten im Reich, Nr. 5a2 Das Interim, Fasz. 1, fol. 78 f.: Brief Ferdinands an Joachim II., 26. September 1548, hier fol. $78^{v}=$ MüLLER, Zur Geschichte des Interims (wie Anm. 8), S. 58 f.

143 Vgl. Issleib, Das Interim in Sachsen (wie Anm. 6), S. 209 f.; Müller, Zur Geschichte des Interims (wie Anm. 8), S. 55-57. - Tatsächlich fand dieses Treffen nicht schon einen Tag vorher statt, wie das Einladungsschreiben suggeriert; vgl. PKMS 4, Nr. 90, S. 132: Kf. Moritz an Kf. Joachim, Torgau, 10. September 1548. Siehe zur korrekten Datierung ebd., Nr. 96, S. 140: Abschied von Jüterbog, 17. September 1548.

$144 \mathrm{Vgl}$. Hans-Ulrich Delius, Religionspolitik und kirchliche Ausgleichsbemühungen des Kurfürsten Joachim II. von Brandenburg, in: Jahrbuch für Berlin-Brandenburgische 
Im Anschluss traten am 18. Oktober in Torgau ${ }^{145}$ die kursächsischen Theologen und Räte ${ }^{146}$ zusammen, um die Ausarbeitung der neuen Kirchenordnung voranzutreiben. Katholiken waren - anders als zuvor in Pegau - diesmal nicht geladen; stattdessen aber Johann Agricola, der jedoch nie in Torgau angekommen ist. Der Grund für sein Fehlen bleibt unbekannt. ${ }^{147}$

Auf der Beratung in Torgau ergriffen nun die weltlichen Räte die Initiative und legten den Theologen ihrerseits einen Entwurf zur Begutachtung vor. ${ }^{148}$ Oliver K. Olson sieht hierin „another fateful step toward a state church“. ${ }^{149}$ Die Räte rechtfertigten ihr Vorgehen mit der Bedrohung durch Kaiser und König, die stetig den Druck auf den Kurfürsten erhöhten. ${ }^{150}$ Die Annahme dieses Vorschlags hätte in den Zeremonien eine Rückkehr zur katholischen Kirche bedeutet. Melanchthon und seine Mitstreiter hatten schon vormals ihren Widerspruch dagegen kundgetan und unterließen es auch diesmal nicht. Es könne nicht angehen, all jenes wieder in die Kirche einzuführen, was die Väter gehalten haben, auch die Adiaphora und willkübrliche Ding. Vielmehr müsse es heißen: [W] as noch im Brauch ist bei den andern, das Adiaphoron ist und göttlicher Lebre nicht zuwider, das wollten wir auch halten. ${ }^{151}$ Demzufolge könnten immerhin die meisten Vorschläge der Räte angenommen werden, doch Ölung, Privat- und Seelenmessen, Heiligendienst und Prozessionen wären nicht statthaft, da sie zu Aberglauben Anlass gäben. 152

Den überarbeiteten Text der Räte sichtend, ${ }^{153}$ meinten die Theologen, nicht alle ihre Forderungen hätten Berücksichtigung gefunden. Beispielsweise wären die anzunehmenden Adiaphora noch genauer zu spezifizieren, und auch über die Gesänge in den Kirchen und die Kirchenstrafen müsse eingehender beraten werden.

Kirchengeschichte 52 (1980), S. 25-87, hier S. 38; IssLeib, Das Interim in Sachsen (wie Anm. 6), S. 212 f.; Müller, Zur Geschichte des Interims (wie Anm. 8), S. 61-63; PKMS 4, Nr. 117, S. 160: Kf. Moritz an Mgf. Johann von Brandenburg, Torgau, 6. Oktober 1548.

$145 \mathrm{Zu}$ den Verhandlungen in Torgau vgl. ausführlich IssLeIB, Das Interim in Sachsen (wie Anm. 6), S. 213-215.

146 In Torgau waren anwesend u. a. die Räte Georg und Christoph von Carlowitz, Georg von Komerstadt und Ludwig Fachs sowie die Theologen Philipp Melanchthon, Georg von Anhalt, Georg Major, Johann Forster und Daniel Greser. Vgl. MoRITz, Interim und Apokalypse (wie Anm. 4), S. 141, Anm. 194.

147 Vgl. Kawerau, Johann Agricolas Antheil (wie Anm. 37), S. 441 f.

148 Vgl. MBW, Nr. 5332: Die kfl. Räte an die Theologen in Torgau: Entwurf einer evangelischen Interimsordnung für Kursachsen, Torgau, 18. Oktober 1548.

149 Olson, Matthias Flacius (wie Anm. 9), S. 112.

150 Vgl. PKMS 4, Nr. 128, S. 167 f.: Kfl. Räte an die Theologen, Torgau, 18. Oktober 1548 $=$ MBW, Nr. 5331 .

151 CR 7, Nr. 4389, S. 174-178: Theologorum in Conventu Torgav. Declaratio, 18. Oktober 1548, hier S. 174 = PKMS 4, Nr. 129, S. 168 f. = MBW, Nr. 5333.

152 Vgl. CR 7, Nr. 4389, S. 175-177.

153 Vgl. MBW, Nr. 5334: Kfl. Räte: Revidierter Entwurf einer evangelischen Interimsordnung für Kursachsen, Torgau, 18. Oktober $1548=$ CR 7, Nr. 4390, S. 178-182, hier S. 178-181. 
Alles in allem solle man nichts übereilen. ${ }^{154}$ Schon in ihrem Änderungsgutachten hatten die Theologen angemahnt, eine landesweite Vereinheitlichung durch Vergleich der kirchlichen Verhältnisse und Konsultierung der Pfarrer anzustellen. Außerdem müsse in der Religionsfrage noch die Verständigung mit den Nachbarn gesucht werden, bevor man weiterschreite. ${ }^{155}$ So wurden die Verhandlungen dann vertagt.

Der Ertrag dieses Torgauer Treffens ist sehr unterschiedlich bewertet worden: Die Spannbreite reicht von Nichtbeachtung, ${ }^{156}$ über eine angeblich völlige Unergiebigkeit der Beratungen, ${ }^{157}$ die Zuschreibung eines rein vorbereitenden Charakters ${ }^{158}$ für das nachfolgende Gespräch in Altzella bis zur Postulierung „eine[s] grossen Schritt[es] vorwärts“. ${ }^{159}$ Letzterem ist zu folgen, da die Initiativergreifung der Räte zu einem ersten tragfähigen Gesetzesentwurf geführt hatte, der nach Aufbau und inhaltlicher Ausrichtung dem späteren Leipziger Interim sehr ähnelte.

Auf den 7. November 1548160 ist jenes Gutachten Joachims und seiner Ratgeber ${ }^{161}$ - Agricola wird hier eine nicht unerhebliche Rolle gespielt haben - datiert, das Moritz auf der Hochzeit seines Bruders in Torgau von den Brandenburgern erbeten hatte: Den Theologen, die fast heftig wuethen vnnd tobenn wieder das Interim, ${ }^{162}$ wäre nicht zu trauen, da sie ihre Meinung ohnehin ständig ändern würden. Nicht selten hätten sie Rebellion und Aufruhr verursacht, so im Bauernkrieg, und nun würden sie gegen Moritz wirken. In Religionsfragen, insbesondere bei den Zeremonien, sei man dem Frommenn Kaiser, ${ }^{163}$ der es nur gut meine und den Frieden erhalten wolle, Gehorsam schuldig. Immerhin würde das Interim die evangelischen Grundforderungen erfüllen. ${ }^{164}$ So fügten die Brandenburger dem Schreiben eine Erklärung über die zeremoniellen Bestimmungen hinzu, wobei der

154 Vgl. MBW, Nr. 5335: Mündlicher Antrag der Theologen an die kfl. Räte in Torgau, Torgau, 18. Oktober $1548=$ CR 7, Nr. 4390, S. $181 \mathrm{f}$.

155 Vgl. CR 7, Nr. 4389, S. 177 f.

156 So übergeht z. B. Scheible, Melanchthon. Eine Biographie (wie Anm. 9), S. 194 f. das Treffen.

157 Vgl. Koch, Der Ausbruch des adiaphoristischen Streits (wie Anm. 7), S. 184.

158 Vgl. Gehrt, Ernestinische Konfessionspolitik (wie Anm. 11), S. 46; MehlHausen, Der Streit um die Adiaphora (wie Anm. 7), S. 117.

159 Simon Issleib, Moritz von Sachsen als evangelischer Fürst. 1541-1553, in: Beiträge zur sächsischen Kirchengeschichte 20 (1907), S. 1-213, hier S. 194; vgl. REICHERT, Amsdorff und das Interim (wie Anm. 9), S. 124.

160 Nicht auf den 10. November, wie beispielsweise bei Matthias Flacius, Wider das Interim (1549), bearb. von Johannes Hund, in: Dingel, Der Interimistische Streit (wie Anm. 87), S. 742-770, hier S. 745 zu lesen. An diesem Tag wurde nur das Begleitschreiben angefertigt.

161 Vgl. PKMS 4, Nr. 152, S. 196-201: Kf. Joachim an Kf. Moritz (Erklärung und Kirchenordnung zum Interim), Cölln/Spree, 7. November 1548 = Abdruck bei Müller, Zur Geschichte des Interims (wie Anm. 8), S. 64-96. - Vgl. dazu die Analyse ebd., S. 96-103; Delius, Religionspolitik und kirchliche Ausgleichsbemühungen (wie Anm. 144), S. 39 f.

162 Zit. nach Müller, Zur Geschichte des Interims (wie Anm. 8), S. 64.

163 Zit. nach ebd., S. 66.

164 Vgl. ebd., S. 70. 
Messkanon ausführlich abgehandelt wurde, der bis auf wenige Veränderungen im alten Ritus weitergeführt werden könne. ${ }^{165}$ Dass Joachim und Agricola mit diesem Votum trachteten, auf den Fortgang der Verhandlungen in Kursachsen einzuwirken, ist augenscheinlich.

Bereits um den 16. November hatten sich die kursächsischen Theologen und Räte ${ }^{166}$ in Altzella bei Nossen einzufinden, ${ }^{167}$ um die Interimsberatungen wieder aufzunehmen. ${ }^{168}$ Nachdem die Theologen am 20. November ein Gutachten zur Überarbeitung der Heinrichs-Agende von 1539 vorgelegt hatten, ${ }^{169}$ stellten die Räte den Theologen eine überarbeitete Fassung der Torgauer Artikel zur Diskussion und versäumten nicht, auf die Konsequenzen hinzuweisen, die zu viel Starrsinn gegen den Kaiser nach sich ziehen könnte. Daher müsse Karl V. in der Religion Gehorsam und Versöhnlichkeit angezeigt werden, um größerem Schaden vorzubeugen. 170

Die Theologen gaben sich überwiegend einverstanden und friedfertig, aber offentliche abgöttische Ceremonien ${ }^{171}$ wollten sie nicht dulden. So könne man den Bischöfen die Ordinierung der Priester nur dann erlauben, wenn sie die reine Lehre nicht unterdrücken würden. Bis dahin seien weiterhin die Superintendenten zuständig. ${ }^{172}$ Nur beim Messkanon und dem Chrisma, dem geweihten Salböl, bestünde noch Uneinigkeit mit den Räten. Darüber wolle am liebsten auf einem Konzil beraten werden. Zunächst könne man den Bischöfen mitteilen, wie sehr man ihnen in den Adiaphora entgegengekommen sei, und sie wegen des Kanons

165 Vgl. ebd., S. 77-91.

166 Anwesend waren von den Theologen Georg von Anhalt, Philipp Melanchthon, Johann Forster, Georg Major, Johannes Pfeffinger, Daniel Greser, Johannes Bugenhagen, Caspar Zeuner und Anton Lauterbach sowie der Gelehrte Joachim Camerarius; von den Räten waren Georg und Christoph von Carlowitz, Melchior von Ossa, Ludwig Fachs und Georg von Komerstadt zugegen. Vgl. MBW, Nr. 5350: Gutachten für Kf. Moritz von Sachsen, Altzella, 20. November 1548. - Dass sich der Kurfürst persönlich in Altzella aufgehalten hätte, wie beispielsweise bei Flacius, Wider das Interim (1549), bearb. von Hund (wie Anm. 160), S. 745 angeführt, ist unwahrscheinlich, da Moritz aus Dresden und Lohmen zur Zeit der Verhandlungen Briefe an Joachim II. (PKMS 4, Nr. 177), seine Frau Agnes (ebd., Nr. 178) und an Herzogin Katharina (ebd., Nr. 181) sandte.

167 Müller, Zur Geschichte des Interims (wie Anm. 8), S. 103, Anm. 3 erbringt den Nachweis, dass die in CR 7, Nr. 4404-4409 getätigten Datierungen nicht zutreffend sind. Demnach hätten die Hauptverhandlungen vom 20. bis 22. November stattgefunden.

$168 \mathrm{Zu}$ den Beratungen in Altzella vgl. IssLeib, Das Interim in Sachsen (wie Anm. 6), S. 216218; Olson, Matthias Flacius (wie Anm. 9), S. 116-118; Wartenberg, Das Augsburger Interim und die Leipziger Landtagsvorlage (wie Anm. 8), S. 22-25.

169 Vgl. PKMS 4, Nr. 175, S. 221 f.: Erstes Bedenken der Theologen [...] an die Räte, Zella, 20. November $1548=$ CR 7, Nr. 4404, S. 198-204 = MBW, Nr. 5350.

170 Vgl. PKMS 4, Nr. 174, S. 220 f.: Erste Schrift der Räte an die Theologen, Zella, 20. November $1548=$ CR 7, Nr. 4405, S. 207-209 = MBW, Nr. 5352.

171 CR 7, Nr. 4406, S. 209-212: Theologi ad Consiliarios, Altzella, hier S. $210=$ PKMS 4, Nr. 176, S. 222 f. - hier Datierung auf den 21. November 1548.

172 Vgl. CR 7, Nr. 4406, S. 211. 
konsultieren. ${ }^{173} \mathrm{Im}$ daraufhin zusammengestellten und einstimmig angenommenen Interim Cellense werden neben anderen Bestimmungen auch die nun gültigen, zu Einigkeit und Gleichheit dienlichen Adiaphora genannt: Firmung, Ölung, Teile der alten Messe, Bilder, Gesänge, Festkalender, Fastenregelungen, besondere Kleider für den Priester etc. Das gelte aber unter der Voraussetzung, dass damit kein Aberglauben verbunden werde. ${ }^{174}$ Nikolaus Müller hat nachweisen können, dass viele der neu aufgenommenen Bestimmungen ihren wortwörtlichen Ursprung in der märkischen Denkschrift vom 7. November hatten. ${ }^{175}$ Die weitere Entwicklung sollte noch zeigen, ob es das tatsächlich wert gewesen war, Zugeständnisse in den Zeremonien zu offerieren, um die reine Lehre zu bewahren.

\section{Vom sächsischen Sonderweg zum brandenburgisch-sächsischen Gemeinschaftsprojekt. Der Theologentag zu Jüterbog}

Die innersächsischen Verhandlungen waren durch das Treffen in Altzella zwar weitestgehend abgeschlossen, dennoch blieben die kursächsischen Theologen mit Gewissensbissen zurück. Sie hätten so weit nachgegeben, als aufs Aeußerst ibnen mit Gerwissen möglich gewesen, und wird schwer seyn, bei dem Volk diese beschwerliche Rede zu stellen. ${ }^{176}$ Die Dienste der Theologen des albertinischen Sachsens wurden aber weiterhin von ihrem Landesherrn in Anspruch genommen, hatte dieser doch vorgegeben, mit Joachim II. in der Interimsproblematik gemeinsam handeln zu wollen. Während der brandenburgische Kurfürst und sein Hofprediger die Reunion mit der katholischen Kirche aus Überzeugung anstrebten, waren Moritz und seine Theologen nicht bereit, die evangelische Lehre preiszugeben. Um das zu erreichen, boten sie an, Zugeständnisse in den Zeremonien zu akzeptieren. Die Brandenburger trachteten überdies danach, noch weiter auf die Sachsen einzuwirken und sie zur Annahme des canon missae (Messkanon), des lateinischen Hochgebets der katholischen Kirche, zu bewegen. Dieses Ansinnen hatte Joachim II. schon in seinem Schreiben vom 7. November 1548 ganz offen kundgetan.

Um die Beratungen zwischen Kursachsen und Kurbrandenburg über das Interim zu einem Abschluss zu bringen, wurde Jüterbog als Tagungsort bestimmt. Das vermag nicht zu überraschen, da die Stadt mit ihrer verkehrsgünstigen Lage zwischen Brandenburg und Sachsen ohnehin ein gern gewählter Treffpunkt für beide Fürsten war. Die Exklave des zum Niedersächsischen Reichskreis gehörenden Erzstifts Magdeburg galt für die umliegenden Landesherrn als ,neutrales' Gebiet,

173 Vgl. PKMS 4, Nr. 180, S. 225: Dritte Schrift der Theologen an die Räte, Zella, 22. November $1548=$ CR 7, Nr. 4408, S. 214 f. = MBW, Nr. 5357.

174 Vgl. MBW, Nr. 5359: Entwurf einer evangelischen Interimsordnung für Kursachsen (der „Zellische Abschied“), Altzella, 22. November $1548=$ CR 7, Nr. 4409, S. 215-221.

175 Vgl. Müller, Zur Geschichte des Interims (wie Anm. 8), S. 104 f.

176 CR 7, Nr. 4408, S. 214 = PKMS 4, Nr. 180, S. 225 = MBW, Nr. 5357. 
sodass einige obersächsische Kreistage des 16. und 17. Jahrhunderts und zahlreiche offizielle wie inoffizielle Zusammenkünfte hier abgehalten wurden. ${ }^{177}$ Dem Treffen vom 16./17. Dezember 1548 ging ebenfalls in Jüterbog eine Zusammenkunft der weltlichen Räte beider Landesherren am 29./30. November voraus. Sie berieten über mögliche Vorgehensweisen, um die Freilassung Philipps von Hessen, der sich seit dem letzten Krieg entgegen einem Versprechen Karls V. an Moritz in kaiserlicher Haft befand, zu erreichen. ${ }^{178}$

Laut Melanchthon war die Jüterboger Konferenz von Joachim angeregt worden. ${ }^{179}$ Am 6. Dezember ging das Einladungsschreiben von Kurfürst Moritz aus. Der Wittenberger Theologe hatte sich zehn Tage darauf in Jüterbog einzufinden. ${ }^{180}$ Zugegen waren neben den beiden Kurfürsten und Melanchthon noch Georg von Anhalt, Johann Agricola, der Leipziger Theologe Johannes Pfeffinger, der Dresdner Superintendent Daniel Greser, der Leipziger Gelehrte Joachim Camerarius und einmal wieder der katholische Bischof von Naumburg Julius Pflug. ${ }^{181}$

Melanchthon war mit der Teilnahme des ihm widerwärtigen Agricola nicht einverstanden. So unterrichtete er im Vorfeld Georg von Anhalt über seine Einladung nach Jüterbog. Von dem zu behandelnden Gegenstand und den Streitparteien war er nicht in Kenntnis gesetzt worden, vermutete jedoch das Kommen der Märker mit Islebium, der sicher einen verbesserten Messkanon vorstellen wolle. Dies hätte zum Ziel, alle Artikel des Interims schrittweise verdeckt einzuführen. Die Gefahr, dass er solches als vorgebliche Autorität absegnen solle, damit die Pfarrer folgsam wären, sah der Theologe durchaus. Er fragte: Aber welcher Lärm

177 Vgl. zu den Kongressen und Kreistagen Erich Sturtevant, Chronik der Stadt Jüterbog, Jüterbog 1935, S. 307-311; Ralf Gebuhr/Frank Göse/Norbert Gossler, Im Netz der Mächte. 400 Jahre Fürstentag in Jüterbog. Begleitbroschüre zur Sonderausstellung, Jüterbog 2011.

178 Vgl. PKMS 4, Nr. 182, S. 226 f.: Instruktion von Kf. Moritz für Sebastian von Wallwitz und Ulrich Mordeisen für die Verhandlung am 29.11. zu Jüterbog, Dresden, 23. November 1548 .

179 Vgl. MBW, Nr. 5383: Melanchthon an den Rat der Stadt Regensburg, Wittenberg, 16. Dezember 1548.

180 Vgl. ebd., Nr. 5372: Kf. Moritz an Melanchthon, Dresden, 6. Dezember 1548.

181 Vgl. beispielsweise Carl GotTlieb EtTmüller, ANNALES der Kreyß-Stadt Jüterbog [...], Manuskript, Jüterbog o. J., S. 264; Flacius, Wider das Interim (1549), bearb. von Hund (wie Anm. 160), S. 762, Anm. 64; Johann Gottlieb Schulze, ANNALES der Creiß-Stadt Jüterbog [...], Manuskript, Jüterbog 1828, S. 116; Sturtevant, Chronik der Stadt Jüterbog (wie Anm. 177), S. 309. - Camerarius wird in der Literatur des Öfteren übergangen, obwohl seine Anwesenheit sehr wahrscheinlich ist. So schrieb er Melanchthon, dass er nur ihm zuliebe nach Jüterbog komme. Vgl. MBW, Nr. 5380: Joachim Camerarius an Melanchthon, Leipzig, 11. Dezember 1548. - Die Aussage von Wartenberg, Das Augsburger Interim und die Leipziger Landtagsvorlage (wie Anm. 8), S. 21, kein katholischer Bischof habe seit Pegau an Verhandlungen über das Interim teilgenommen, ist nicht zutreffend, weil Pflug in Jüterbog war. - Laut GotTrR(I)ED Неснт, Denkwürdigkeiten der uralten sächsischen Stadt Jüterbog. Aus dem Lateinischen übertragen von Herbert Wegener (Berlin), Typoskript, Jüterbog $1997=1707$, $\$ 24$, S. 2 sei auch noch Georg Major in Jüterbog dabei gewesen. Das ist weder belegt noch an einer anderen Stelle aufgegriffen worden. 
wird sein, wenn wir mit Eisleben gesehen werden? Agricola würde alle Missbräuche wieder einführen wollen, und er hätte sich dafür mit einem großen Geschenk bestechen lassen. All diese Umstände sorgten bei Melanchthon für großen Unmut. Er bat Georg von Anhalt, ihm mitzuteilen, ob auch er in Jüterbog sein würde und ob er ihm raten könne, sich überhaupt an einem solchen Treffen zu beteiligen. ${ }^{182}$ Nach eigener Aussage gegenüber Camerarius hätte Melanchthon sich längst aus den Verhandlungen zurückgezogen, wenn ihm dafür nicht unterstellt würde, aus Vorurteil gegen Moritz zu handeln. Zu jenem Zeitpunkt sah er die Möglichkeit einer freien Disputation gar nicht mehr gegeben, da alle anderen Gruppierungen die Gelehrten ausschalten wollen würden. ${ }^{183}$ Vor dem Hintergrund dieses gefühlten Bedrohungsszenarios wird dann auch die zaudernde Haltung Melanchthons verständlich.

Ebenso wollten die von den Kurfürsten bewusst nicht nach Jüterbog geladenen radikalen Lutheraner auf den großen Theologen Einfluss nehmen, um allen weiteren Aufweichungen von evangelischer Lehre und Glaubenspraxis vorzubeugen. Flacius hatte sich kurz vor der Abreise Melanchthons mit jenem unterredet und ihm einen Tag darauf eine Materialsammlung über die Messe übersandt, um ihn in seiner Standfestigkeit zu bestärken. ${ }^{184}$ Denn der als Praeceptor Germaniae bekannte Theologe war von steten Selbstzweifeln geplagt - so auch vor dem Konvent in Jüterbog, wie Flacius in einer seiner Druckschriften berichtet: In der Nacht zum 14. Dezember hatte Melanchthon einen sonderbaren Traum, den er Flacius in einem vertraulichen Gespräch mitteilte: Einer seiner Nachbarn in Landsknechtskleidern hätte ihn gebeten, den Glaser zu bestellen, sodass dieser Fenster herstellen möge. Nachdem das geschehen war, kam der Glaser bald wieder und beschwerte sich darüber, dass er nun eine papistische Messe halten solle. Melanchthon deutete den Traum so, dass er selbst der Glaser sei, der etliche fenster/ das ist/ etwas zum scheine machen solle. Aber warlich alles was gehandelt wird/ gehet gewislich dahin/ das die Papistische Messe ond das Bapstumb widder auffgerichtet werde. ${ }^{185}$ Dafür sollte Melanchthon in Jüterbog nach eigener Erkenntnis benutzt werden, und er schwor sich zu widerstehen. Obwohl der Wittenberger Theologe mit seinen Träumen recht offen umging, empfand er die Drucklegung durch Flacius, der ihm - aufgrund seines Handelns wider besseres Wissen - Heuchelei unterstellte, dann doch als Vertrauensbruch. ${ }^{186}$

182 Vgl. CR 7, Nr. 4424, S. 234: Melanchthon an Fürst Georg von Anhalt, Lat., Wittenberg, 11. Dezember $1548=$ MBW, Nr. 5377.

183 Vgl. MBW, Nr. 5381: Melanchthon an Joachim Camerarius, Wittenberg, 12./13. Dezember $1548=$ CR 7, Nr. 4402, S. $193 \mathrm{f}$.

184 Vgl. MBW, Nr. 5382: Matthias Flacius an Melanchthon, Wittenberg, vor dem 16. Dezember 1548.

185 Matthias Flacius Illyricus, Eine entschuldigung Matthiae Flacij Jllyrici/ an einen Pfarherr. Jtem desselben/ was da sey die Kirchen verlassen odder nicht verlassen. Jtem zween Trewme Philippi, Magdeburg 1549 (VD 16: F 1369), fol. B iijv.

186 Vgl. Kaufmann, Das Ende der Reformation (wie Anm. 4), S. 307, Anm. 489. 
Der Vertrag, den die beiden Kurfürsten am 17. Dezember 1548 unterschrieben, entsprach zum überwiegenden Teil den Altzellaer Artikeln. ${ }^{187}$ So sollten weiterhin die Adiaphora zur Herstellung der äußeren Einheit der Kirche dienen: Dergleichen sol man auch halten in adiaphoris, das ist in mitteln Dingen, was die alten christlichen Lebrer gebalten und bey den anderen theil, den Katholiken, noch im Brauch blieben ist. ${ }^{188}$ In diesem Sinne wurden alle den kursächsischen Theologen vormals abgerungenen Konzessionen auch dieses Mal bewilligt. Tatsächlich blieb es dabei aber nicht. Einige Formulierungen sind womöglich auf Druck Pflugs verschärft worden. Hieß es im Zellaer Text noch: [D]arum mag man binfürder solche Oelung nach der Apostel Gebrauch halten, wurde die Erlaubnis nun zur Verbindlichkeit erklärt und mag durch soll ersetzt. Außerdem geschähe die Salbung - so ein in Jüterbog beschlossener Zusatz - Im Nabmen des Herren. ${ }^{189}$ Ansonsten waren die Veränderungen eher marginal und nicht inhaltlicher Natur.

Es ist bekannt, dass die Brandenburger zusätzlich auch den Messkanon wieder aufrichten wollten. Zum einen hätte das die vollständige liturgische Wiederangleichung an die Altkirche bedeutet, zum anderen wären zentrale Lehrgrundsätze betroffen gewesen, war in diesem lateinischen Hochgebet doch der Opfercharakter der Messe und die von den Protestanten abgelehnte Mittlerfunktion des Priesters zu Gott festgelegt. Ahnend, dass Agricola sein Anliegen weiter verfolgen würde, hatte Melanchthon im Voraus eine Abhandlung über das Messopfer verfasst: $\mathrm{Zu}$ allen Zeiten seien Opfer und Zeremonien missbraucht worden. Indem man davon ausging, zwecks Sündenvergebung Opfer erbringen zu können, seien noch mehr Sünden verübt worden. Zudem müssten die Sakramente im Glauben empfangen werden, da die gedankenlose Handlung und Zelebrierung des Priesters ohne Glauben nichts nütze. So könne es sich beim Abendmahl nur um ein Lobund Gedächtnisopfer, nicht um ein Opfer zur Sündenvergebung handeln, da jenes

187 Eine Abschrift des augenscheinlich im Zweiten Weltkrieg verbrannten Originals (Landeshauptarchiv Sachsen-Anhalt (im Folgenden: LHASA), Z 4 Anhaltisches Gesamtarchiv. Alte Ordnung, I, 124, Nr. 23: Vertrag zu Jüterbog in Religionsangelegenheiten, 1548) befindet sich im HStA Dresden, 10024 Geheimer Rat, Loc. 10298/1 Interim Domesticum Secundum, fol. 269-279: Beyder Churfürsten, zu Sachsen und Brandenburg, Vereinigung in Religions-Sachen, zu Güterbach, 1548. Zum zehnten Jahrestag des Vertrags scheint auch ein Druck mit polemischen Kommentaren ausgefertigt worden zu sein: Moritz/Joachim II., Hertzogs Moritzen zu Sachsen/ vnd des Marggrafen zu Brandenburg/ beyder Churfürsten vereinigung/ des JNTERIMS halben, Regensburg 1558 (VD 16: S 830). Einleitung und Schluss des Vertrags finden sich jeweils in GStA PK, I. HA, Rep. 13 Religionsstreitigkeiten im Reich, Nr. 5a2 Das Interim, Fasz. 2 Das Interim, fol. 116; CR 7, Nr. 4426, S. 248 f.: Decretum Iuterbocense, 17. Dezember 1548; PKMS 4, Nr. 212, S. 258, 260, Anm. zu T 5. Die Version aus dem HStA Dresden soll im Folgenden die maßgebliche sein.

188 HStA Dresden, 10024 Geheimer Rat, Loc. 10298/1, fol. 270v.

189 Ebd., fol. 273v . Vgl. die Veränderungen im Artikel über die Ölung bei CR 7, Nr. 4409, S. 218. 
nicht durch das Neue Testament belegt sei. Man müsse allein darauf vertrauen, dass Jesus für die Menschen am Kreuze gestorben sei. ${ }^{190}$

Flacius berichtet, dass Agricola in Jüterbog für das Eintreten zugunsten der Wiedereinführung des Messkanons heftig angegangen wurde: In engeren Beratungen, an denen sich nur noch die Kurfürsten beteiligten, warf Georg von Anhalt Agricola eine Kehrtwende vor, da er sich 1526 auf dem Reichstag zu Speyer und in einer im Folgejahr erschienenen Druckschrift noch ganz anders geäußert hatte. Agricola erwiderte, dass sich die Umstände geändert hätten; die Katholiken seien nun bekehrt. Damit könne dann auch der Messkanon angenommen werden. Georg von Anhalt hielt dagegen, dass der Kanon an sich schon abgöttisch sei. Indem die Katholiken diesen aber unverändert ließen, würden sie zeigen, wie wenig sie sich gewandelt hätten: Er ist vnnd bleibt der alte Canon und bebelt seinen vorigen schmack. ${ }^{191}$

Sicherlich ist hier Vorsicht geboten, weil Flacius mit seiner Schilderung eigene Ziele verfolgte. Dass Sondergespräche stattfanden, wurde aber auch von anderer Seite überliefert. So soll Julius Pflug die beiden Kurfürsten abseits der übrigen Teilnehmer bearbeitet haben. Das scheinen Melanchthon und Bugenhagen zu bestätigen, als sie den märkischen Pfarrern versicherten, keine Kenntnis über den genauen Wortlaut des Jüterboger Vertrages zu besitzen. Sie wären nicht zugegen gewesen, als die Kurfürsten ihre Unterschriften unter den Text setzten. ${ }^{192}$ Es deutet vieles darauf hin, dass zu den diversen Verhandlungspunkten verschiedene Theologen zu Rate gezogen wurden, um zügig zu belastbaren Ergebnissen zu gelangen und ewige Dispute zu vermeiden.

In der Vorrede des Vertrags suggerierten Moritz und Joachim II. die Übereinstimmung der Artikel mit dem Augsburger Interim, um den Kaiser zu beruhigen. Es wären lediglich weitere Beratungen notwendig gewesen, weil vielerley Mißverstand vorgefallen. ${ }^{193}$ Sie verpflichteten sich außerdem, diese sächsisch-brandenburgische Interpretation des kaiserlichen Religionsgesetzes in rechten christlichen

190 Vgl. MBW, Nr. 5384: Abhandlung über das Messopfer, Jüterbog, 16. Dezember 1548. Hier wird auch der Nachweis erbracht, dass die bei CR 4, Nr. 2238, S. 309-316 edierte und nachträglich auf 1541 datierte Textversion erst für den Jüterboger Konvent erstellt worden ist, während der bei CR 7, Nr. 4425, S. 234-247 und dort der Tagung von Jüterbog zugeschriebene Text bereits um den 24. Oktober 1548 entstanden sein muss; vgl. MBW, Nr. 5343: Abhandlung über das Messopfer, Wittenberg, ca. 24. Oktober 1548. Immerhin baut MBW, Nr. 5384 merklich auf Nr. 5343 auf.

191 Vgl. Flacius, Wider das Interim (1549), bearb. von Hund (wie Anm. 160), S. 748, 761763 und Anm. 64; zit. nach ebd., S. 762. Vgl. weiterhin Kawerau, Johann Agricolas Antheil (wie Anm. 37), S. 442 f.; Olson, Matthias Flacius (wie Anm. 9), S. 123; Waschвüsch, Alter Melanchthon (wie Anm. 7), S. 97 f.

192 Vgl. Heснт, Denkwürdigkeiten (wie Anm. 181), \24, S. 2; MBW, Nr. 5401: Johannes Bugenhagen und Melanchthon an Georg Buchholzer und die anderen Prediger in Berlin, Wittenberg, 11. Januar 1549 = CR 7, Nr. 4460, S. 299-301.

193 HStA Dresden, 10024 Geheimer Rat, Loc. 10298/1, fol. 269'-v. Vgl. in dieser Interpretation Kawerau, Johann Agricolas Antheil (wie Anm. 37), S. 444. 
Verstand bey unseren Unterthanen, mit Jhrer Bewilligunge, ins Werck zubringen. ${ }^{194}$

Dennoch war in der Frage nach der Wiedereinführung der katholischen Messe keine Einigkeit erreicht worden, wie die Kurfürsten am Schluss des Jüterboger Textes bekannten: So wollen wir doch uns darauff ferner berathschlagen, wie deme zuthuen, und wie man deshalben auch möge zu christlicher Vergleichunge und Verainigunge kommen. ${ }^{195}$

Nikolaus Müller hat als „diplomatisches Meisterstück“ gewertet, dass es Joachim gelang, „Moritz vor den Interimswagen zu spannen“. ${ }^{196}$ Doch die nicht ausgestandenen Differenzen beim Messkanon müssen in die Überlegungen für eine Bewertung der Jüterboger Konferenz einbezogen werden. Gerade dem erbitterten Widerstand Melanchthons und Georgs von Anhalt ist die Ablehnung des Messopfers und -kanons zu verdanken. ${ }^{197}$ Indem Joachim II. durch seine Unterschrift zusicherte, die niedergeschriebenen Artikel einzuführen, hatte er sich vertraglich der albertinischen Interimsposition angeschlossen, ${ }^{198}$ auf deren Genese er gleichwohl nicht unerheblichen Einfluss genommen hatte. Moritz ließ sich keineswegs von dessen interimistischer Position vereinnahmen und wahrte innere Distanz; er pflegte später seinen brandenburgischen Kollegen spöttisch das dicke Interim ${ }^{199} \mathrm{zu}$ nennen.

Am 18. Dezember 1548 reisten die Teilnehmer der Jüterboger Konferenz, auf der zum wiederholten Male über eine etwaige Freilassung Philipps von Hessen beraten worden war, ${ }^{200}$ aus der Stadt ab. ${ }^{201}$ Anders als es die Äußerungen Melanchthons vor der Jüterboger Tagung hätten vermuten lassen, zeigte er sich mit den Ergebnissen recht zufrieden.202 An Johannes Bugenhagen vermeldete er, dass von dem Treffen nur Gutes zu berichten sei. Über die Beschlüsse von Altzella wolle auch Joachim nicht hinausgehen. Alle Teilnehmer seien über die Einträchtigkeit hoch erfreut gewesen. ${ }^{203}$

194 HStA Dresden, 10024 Geheimer Rat, Loc. 10298/1, fol. 269v

195 Ebd., fol. $278^{\mathrm{v}}-279^{\mathrm{r}}$.

196 Müller, Zur Geschichte des Interims (wie Anm. 8), S. 106. Vgl. weiterhin in dieser Einschätzung Bodo Nischan, Die Interimskrise in Brandenburg, in: Schorn-Schütte, Das Interim 1548/50 (wie Anm. 2), S. 255-273, hier S. 261.

197 So wertet es auch Olson, Matthias Flacius (wie Anm. 9), S. 123.

198 So auch Wartenberg, Das Augsburger Interim und die Leipziger Landtagsvorlage (wie Anm. 8), S. 25, Anm. 45.

199 Zit. nach Issleib, Das Interim in Sachsen (wie Anm. 6), S. 219, Anm. 48.

200 Vgl. PKMS 4, S. 243, Anm.: Franz Kram an Statthalter, Kanzler und Räte zu Kassel, Weißenburg, 20. Dezember 1548.

201 Zumindest für Moritz, Joachim und Melanchthon ist das nachweisbar. Vgl. PKMS 4, Nr. 198, S. 242 f.: Kf. Moritz und Kf. Joachim an die jungen Lg. zu Hessen, Jüterbog, 18. Dezember 1548; MBW, Nr. 5385: Mündlicher Bericht an Johannes Bugenhagen, Wittenberg, 18. Dezember 1548, siehe Hinweise zur Datierung.

202 Entgegen Kawerau, Johann Agricolas Antheil (wie Anm. 37), S. 444, der nur die trübseligen Äußerungen Melanchthons vor dem Zusammentreffen anführt. Damit lässt sich die Niedergeschlagenheit nach der Zusammenkunft aber schwerlich beweisen.

203 Vgl. MBW, Nr. 5385. 
Von Jüterbog heimgekehrt und durch seinen Verbündeten und dessen Theologen vorgeblich bestärkt, gab Joachim II. seine Zurückhaltung in der Interimsfrage für das eigene Land auf. ${ }^{204}$ Johann Agricola brüstete sich, mit den Wittenberger Theologen eine Einigung und damit die Einführung des Interims erreicht zu haben. Er wähnte sich nun angesichts der vorigen Anfeindungen als evangelischer Theologe rehabilitiert. Am 23. Dezember sprach der brandenburgische Hofprediger und Verhandlungsführer dann über die Jüterboger Beschlüsse im Berliner Dom: Da habt ir es nun, lieben leuthe, was Gott vor grosse genade zw Gueterbach gewirckt hatt. Derhalben halt ein jeder sein maul hinfurder vnd belige ond lestere vnschuldige leuthe nicht mebr. Vnd wan dw nun wilt wißen, was das Kayserliche buch oder das Jnterim ist, So sage: es [ist] meines gnedigen hern, vonn Brandenburgk des Churfursten aussgangenn ordnung, vnd glaube den Lugenmeulern nicht mehr, Die jtzt in schanden mussen bestehenn. Die vor in aller welt ausgeschriebenn ond geplaudert, der Kaiser wolle das Euangelion vortilgen, Welchs dw nun horest, das erlogen ist. Dan das ich itzunder vorlesen, haben ja die Theologen zw Wittembergk gestalt. Derhalbenn stehet nun die thur dem Euangelio durch gantz Europa offen. ${ }^{205}$

\section{Die uneindeutigen Beschlüsse des Landtags zu Leipzig}

Um der seit einem halben Jahr vorbereiteten Kompromissformel Gesetzeskraft zu verschaffen - so zumindest das Vorhaben -, wurde für den 21. Dezember 1548 ein vollständiger kursächsischer Landtag zu Leipzig206 einberufen, dem der Religionstext als Landtagsvorlage zur Annahme anheimgestellt wurde. ${ }^{207}$ In der Forschung ist oftmals im Unklaren geblieben, wie der Landtag über das Interim genau entschied, und vor allen Dingen, wie es zu den Beschlüssen kam. Nicht selten wird der Eindruck erweckt, die Landtagsvorlage sei im Ganzen angenommen ${ }^{208}$ oder

204 Vgl. MüLler, Zur Geschichte des Interims (wie Anm. 8), S. 106 f.

205 HStA Dresden, 10024 Geheimer Rat, Loc. 10298/1 Interim Domesticum Secundum, fol. 257-263: Brief Georg Buchholzers und Kollegen an die Wittenberger Theologen, Berlin, 7. Januar 1548, hier fol. 259v $-260^{\mathrm{r}}=\mathrm{CR} 7, \mathrm{Nr} .4455$, S. 292-296 = MBW, Nr. 5398. Vgl. Müller, Zur Geschichte des Interims (wie Anm. 8), S. 118 f.; Kawerau, Johann Agricolas Antheil (wie Anm. 37), S. 444 f.

206 Zum Leipziger Landtag vgl. ausführlich IssLeib, Das Interim in Sachsen (wie Anm. 6), S. 219-223; Moritz, Interim und Apokalypse (wie Anm. 4), S. 142-144; Reichert, Amsdorff und das Interim (wie Anm. 9), S. 127-129; Wartenberg, Das Augsburger Interim und die Leipziger Landtagsvorlage (wie Anm. 8), S. 25-32; PKMS 4, Nr. 210240, S. 252-283 und S. 16-18; CR 7, Nr. 4431-4449, S. 253-286; MBW, Nr. 5386-5394.

207 Die Landtagsvorlage wurde aber nicht schon am 21. Dezember, am Tag ihrer Unterbreitung, abgelehnt, wie bei Flacius, Wider das Interim (1549), bearb. von Hund (wie Anm. 160), S. 746 beschrieben.

208 Vgl. LutTenberger, Glaubenseinheit und Reichsfriede (wie Anm. 7), S. 485; Nischan, Die Interimskrise in Brandenburg (wie Anm. 196), S. 261; Thomas Kaufmann, Geschichte der Reformation, Frankfurt a. M./Leipzig 2009, S. 687. 
abgelehnt worden. ${ }^{209}$ Schon dieser Umstand weist einerseits darauf hin, dass hier zum Teil grundlegende Missverständnisse durch unzulässige Verkürzung vorherrschen müssen, und andererseits, dass sich der Sachverhalt nicht sehr einfach darstellt, sondern einer genaueren Analyse bedarf.

In der Proposition führte Kurfürst Moritz den Grund an, weshalb dieser Landtag einberufen worden sei. Der Kaiser dränge zur Annahme des Interims, obwohl Moritz dem Reichsoberhaupt stets das Versprechen vor Augen geführt habe, in der Religion nichts ändern zu wollen, bis ein Konzil zusammenträte. Doch angesichts der ausgestoßenen Drohungen mögen die Stände über die Landtagsvorlage beraten und dem zustimmen, was sie mit ihrem Gewissen bei den widrigen Zeitumständen vereinbaren könnten. Die drei wichtigsten Punkte seien bewilligt worden: evangelische Rechtfertigungslehre, Abendmahl in beiderlei Gestalt und Priesterehe. In den übrigen Dingen sollten die Gewissen nicht beschwert werden. Sie seien nur zu guter Policey dienstlich. Moritz und seine Räte suggerierten also eine rein politische Dimension. ${ }^{210}$

Den versammelten Ständen wurde nun die Landtagsvorlage das Interim betreffend unterbreitet, die mit dem in Altzella und Jüterbog unterzeichneten Text fast vollständig übereinstimmte. Obwohl dieser Vergleichstext durch das Zusammenwirken weltlicher Räte und Theologen unter obrigkeitlichem Druck gleichermaßen entstanden ist, gelang es den Räten, jenen Text als ,Der Theologen Ratschlag den versammelten Ständen vorzustellen. ${ }^{211} \mathrm{Er}$ setzte sich im Wesentlichen zusammen aus den im Juli 1548 in Meißen verschriftlichten Bedenken der Theologen, der in Pegau verglichenen Rechtfertigungslehre und den Altzellaer Artikeln über die Adiaphora. Hinzugefügt wurde am Ende der Passus: Ibn Andern Artickeln Sein wier erbottig unns derbalben jnn der schriefft und alten lebrern, auch vleissig zu ersehen, und unser Freunden und gnedigen herren denn Bischoffen unnser Bedencken anzuzeigen unnd [...] Christlic zuvorgleichen. ${ }^{212}$

Ritterschaft und Städte schöpften Verdacht ob der Uneindeutigkeit vieler Aussagen. In der Tat war jene Undurchsichtigkeit zur Strategie erhoben worden. War das Augsburger Interim an einigen Stellen nebulös gewesen, um etwa für die Artikel über die Messe und die Rechtfertigungslehre Zustimmung zu erreichen, war es die Landtagsvorlage in den Zeremonie-Bestimmungen. So wurde etwa bei der Taufe nicht direkt die Salbung verlangt, aber verfügt, dass dabei die alten christ-

209 Vgl. Flacius, Wider das Interim (1549), bearb. von Hund (wie Anm. 160), S. 746; GeHrt, Ernestinische Konfessionspolitik (wie Anm. 11), S. 46; Косн, Der Ausbruch des adiaphoristischen Streits (wie Anm. 7), S. 184; Scheible, Melanchthon. Eine Biographie (wie Anm. 9), S. 195.

210 Vgl. PKMS 4, Nr. 210, S. 252: Moritz an die Landschaft (Proposition), Leipzig, 21. Dezember $1548=$ CR 7, Nr. 4431, S. 253-255.

211 Vgl. Wartenberg, Das Augsburger Interim und die Leipziger Landtagsvorlage (wie Anm. 8), S. 25 f.

212 PKMS 4, Nr. 212, S. 254-260: Kfl. Landtagsvorlage zur Religionsfrage („Leipziger Interim“), präs. Leipzig, 21. Dezember 1548, hier S. 260. 
lichen Ceremonien gelert vnnd gebalten werden. ${ }^{213}$ Der Interpretationsspielraum für solche Fragen war dermaßen groß, dass die Stände sich dazu veranlasst sahen, den Theologen ein weiteres Gutachten nun über die angeblich von ihnen allein erstellte Landtagsvorlage abzunötigen. ${ }^{214}$

Melanchthon und seine Mitarbeiter hoben in ihrer zusätzlichen Interpretation vom 22. Dezember den evangelischen Grundcharakter der Bestimmungen von Altzella hervor und erbrachten eine ausführliche Erklärung, weshalb man in den Adiaphora den kaiserlichen Wünschen entgegenkomme: Wenn man dem Kaiser nicht nachgebe, sei Krieg zu erwarten. Sollte man aber in den Kirchen Änderungen vornehmen, würde Betrübniß entstehen. Obwohl sie genau über die Reden derjenigen Bescheid wüssten, die nichts nachgeben wollten, da damit die Herzen beschwert würden, so baben wir bedacht, daß von solchen Mitteldingen nichts zu streiten ist, und sonderlich, so man hoffet, Krieg zu verbüten. Mit den Adiaphora könnten also die Schwachen geschützt werden, die wegen unnötiger Dinge nicht leiden brauchen. Das möge man sich getrost für die nöthigen, großwichtigen, woblgegründeten Sachen aufsparen. Sollte sich der Kaiser mit den offerierten Mitteldingen zufrieden zeigen, wäre das erfreulich. Genüge das dem Herrscher nicht, liege wenigstens ein hinreichender Grund vor, tatsächlich leiden zu müssen. Schließlich habe sich die Kirche immer in servitute befunden - zu manchen Zeiten ärger, zu anderen Zeiten weniger arg. ${ }^{215}$

Wenige Tage darauf billigten Ritterschaft und Städtevertreter die Artikel weitestgehend. Doch neben mehreren kleineren Änderungswünschen bestand ihre größte Sorge in der Anerkennung der bischöflichen Jurisdiktion. Sie äußerten Zweifel daran, ob die papistischen Bischöfe - damit waren Julius Pflug und Johann VIII. von Maltitz gemeint - sich an die Bestimmungen halten würden, ohne die evangelischen Prediger an der Ausübung ihrer Pflichten zu hindern.216

Die Theologen sahen sich dazu berufen, die Bedenken der Stände zu zerstreuen. Nicht sie allein hätten die Artikel der Landtagsvorlage ausgefertigt, sondern dies sei unter Hinzuziehung von Superintendenten und Pfarrern geschehen, sodass es nicht in ihrer Macht stünde, Veränderungen vorzunehmen. Es wäre auf Gottes Gnade zu hoffen, dass nur fähige und gottesfürchtige Bischöfe eingesetzt werden, die der evangelischen Lehre nicht zu schaden trachteten und die ihr Amt recht ausfüllen könnten. ${ }^{217}$

213 Ebd., S. 255.

214 Vgl. PKMS 4, Nr. 211, S. 253: Bedenken von Ritterschaft und Städten zur kfl. Proposition in der Religionsfrage, Leipzig, nach dem 21. Dezember 1548.

215 Vgl. ebd., Nr. 213, S. 261: Bedenken der Theologen, Leipzig, 22. Dezember 1548 = CR 7, Nr. 4432, S. 255-258 = MBW, Nr. 5386.

216 Vgl. PKMS 4, Nr. 222, S. 265: Antwort der Städte auf die Kirchenordnung der Theologen, Leipzig, 24. Dezember $1548=$ CR 7, Nr. 4434, S. 264 f.; PKMS 4, Nr. 223, S. 265 f.: Antwort der Landstände auf die von den Theologen vorgetragene Kirchenordnung, Leipzig, 25. Dezember 1548 = CR 7, Nr. 4435, S. 265-267 = MBW, Nr. 5388.

217 Vgl. MBW, Nr. 5389: Die Theologen an die Landstände in Leipzig, Leipzig, 25./26. Dezember 1548 = PKMS 4, Nr. 225, S. 267 = CR 7, Nr. 4436, S. 267-269. 
Ritterschaft und Städte ließen sich nicht beirren. Solange die alten Missbräuche nicht wieder eingeführt würden, seien sie mit den Vorschlägen der Theologen wohl zufrieden. Aber ihnen fehlte das Vertrauen in die Bischöfe, dass diese den Predigern die evangelische Ausübung ihres Amtes erlauben würden. Bis jene Voraussetzungen nicht erfüllt wären, dürften Konsistorien und Superintendenten ihre Befugnisse nicht an die Bischöfe abgeben. ${ }^{218}$ Allein die Grafen meldeten in ihrem Votum keine Bedenken gegen die Leipziger Landtagsvorlage an. ${ }^{219}$

Während die übrigen Landtagsteilnehmer sich in ihren Religionsvorstellungen nach und nach annäherten, sollten ausgerechnet die beiden anwesenden Bischöfe die Arbeit eines halben Jahres mit nur einer Stellungnahme zunichtemachen. Sie lehnten eine Änderung der kaiserlichen Interimsartikel strikt ab. Zwar würden sie den Landtagsentwurf als dem Augsburger Interim gemäß betrachten wollen, dennoch sei er in vielen Punkten zu stark verändert, als dass sie dem zustimmen könnten. Die Stände sollten das Interim zur Aufrechterhaltung von Ordnung und Frieden nach der Augsburger Fassung einführen und bei Unklarheiten sich an den Kaiser persönlich wenden. Es sei nicht an ihnen, ohne Bewilligung des Kaisers Veränderungen am Interim gutzuheißen. ${ }^{220}$ Das war ein sprichwörtlicher Schlag ins Gesicht der kursächsischen Ständevertreter, Räte und Theologen, war doch Pflug an den Verhandlungen zum sächsisch-brandenburgischen Sonderweg einige Tage zuvor in Jüterbog selbst beteiligt gewesen.

Die Städtevertreter reagierten umgehend. Sie wollten den bischöflichen Einwürfen nicht stattgeben und plädierten dafür, dass der Kurfürst weitere Beratungen mit den Bischöfen und den Theologen organisieren sollte.221 Das sagte Moritz in seiner Antwort an die Stände auch zu. Noch dort auf dem Landtag wollte er mit den Bischöfen weitere Verhandlungen anstrengen, weswegen die Stände Verordnete für die Unterredungen abstellen sollten.222 Dagegen verweigerten sie sich aber, weil es ihnen an Kompetenz mangelte. Die Stände appellierten dafür, daß Ew. Chf. G. solche Handlung mit Rath bedenken, auch im Beiseyn der Herrn Theologen gnädigst fürnebmen ließen. Darüber hinaus beharrten sie auf ihrer Ablehnung der bischöflichen Jurisdiktion, sollten diese Verhandlungen dazu führen, dass die Vergleichung mit den Bischöfen auf Basis der Landtagsvorlage geschähe. ${ }^{223}$

218 Vgl. CR 7, Nr. 4438, S. 270-272: Equites et urbes ad Electorem, 28. Dezember 1548.

219 Vgl. PKMS 4, Nr. 229, S. 271: Bedenken der Gf. zum Interim, Leipzig, Ende Dezember $1548=$ CR 7, Nr. 4439, S. 272-274.

220 Vgl. PKMS 4, Nr. 227, S. 269 f.: Bedenken von Bf. Johann VIII. von Meißen und Bf. Julius Pflug von Naumburg-Zeitz, Leipzig, Ende Dezember 1548 = CR 7, Nr. 4444, S. 277-280.

221 Vgl. PKMS 4, Nr. 228, S. 270: Erwiderung der Städte auf das Bedenken von Bf. Johann VIII. von Meißen und Bf. Julius Pflug von Naumburg-Zeitz, Leipzig, Ende Dezember $1548=$ CR 7, Nr. 4445, S. 280 f.

222 Vgl. PKMS 4, Nr. 230, S. 271 f.: Das 4. Vortragen des Kf., Leipzig, 30. Dezember 1548 $=\mathrm{CR} 7, \mathrm{Nr} .4442, \mathrm{~S} .275 \mathrm{f}$

223 Vgl. CR 7, Nr. 4446, S. 282-284: Equites et urbes ad Electorem, in conv., hier S. $283=$ PKMS 4, Nr. 232, S. 273, hier datiert auf den 31. Dezember 1548. 
In einer abschließenden Antwort sicherte Moritz den Ständen zu, mit den Bischöfen auch über ihre Kompetenzen und Amtsführung weiterhin zu verhandeln. Zusätzlich wolle er eine Kirchenordnung erarbeiten lassen, die sich an den Bedenken der Theologen und den Bewilligungen der Stände ausrichte. ${ }^{224}$ Letztere legten in ihrem endgültigen Antwortschreiben vor ihrer Verabschiedung am 1. Januar 1549 größten Wert darauf, die Bedingungen für eine mögliche Kirchenordnung zu betonen, daß solches Ew. Chf. G. gnädigstem Erbieten nach anders nicht, denn der Theologen Bedenken und ibrer Erklärung und unsrer geschebenen Berwilligung nach geschehe. 225

Die Landtagsvorlage ist von den Ständen also bewilligt worden - zumindest zum überwiegenden Teil -, und das wollten sie auch so verstanden wissen. Jedoch stellte es eine Niederlage für die weltlichen Räte dar, dass ihre Rechnung nicht aufgegangen war. Dies ist nicht einer angeblichen Renitenz der Stände zuzuschreiben, wie nicht selten zu lesen, sondern vor allem der Verweigerungshaltung der beiden katholischen Bischöfe. Sie erklärten sich lediglich dazu bereit, beim Papst um einen Indult zugunsten des Abendmahls in beiderlei Gestalt und der Priesterehe als unbedingt notwendige Voraussetzung zur Annahme des Interims anzufragen. ${ }^{226}$ Die Interessengegensätze haben sich durch uneindeutige Formulierungen und das Verschweigen wichtiger Hindernisse eben nicht ausräumen lassen, zumal die Zustimmung der katholischen Autoritäten nicht sicher war, tatsächlich sogar eher unwahrscheinlich schien.

Für manche Zeitgenossen war auch gar nicht ersichtlich, was überhaupt beschlossen worden war. Melanchthon zeigte sich in einem Brief an Markgraf Johann vom 24. Januar 1549 im Ganzen zwar zufrieden damit, dass die Lehre unangetastet blieb und insbesondere die Ritterschaft Rückgrat bewiesen hatte; es wäre dennoch wünschenswert gewesen, der Landtag hätte eindeutigere Beschlüsse gefasst. Melanchthon prognostizierte dem Interim zudem keine lange Lebensdauer. In zwei Jahren wäre der ,Spuk' vorbei. Doch bis dahin sei Unruhe und Zerrüttung zu erwarten. Er für seine Person wolle nicht weiter nachgeben, als er es ohnehin schon getan habe. 227

224 Vgl. PKMS 4, Nr. 233, S. 273-275: Abschließende Antwort von Kf. Moritz auf die Bedenken von Ritterschaft und Ständen, Leipzig, 1. Januar 1549, hier S. 274 = CR 7, Nr. 4447 A, S. 284 f.

225 CR 7, Nr. 4447 B, S. 285.

226 Vgl. IssLeib, Das Interim in Sachsen (wie Anm. 6), S. 223. - Die beiden Bischöfe hielten den Kaiser, dem sie berichteten, Moritz würde sich für das Augsburger Interim einsetzen, stets auf dem Laufenden. Außerdem baten sie den Kaiser, beim Papst um den Indult anzusuchen; vgl. PKMS 4, Nr. 234, S. 275 f.: (Bf. Johann von Meißen und Bf. Julius von Naumburg-Zeitz) an Ks. Karl V., Leipzig, nach dem 20. Dezember 1548; Nr. 239, S. 281: Bf. Johann VIII. von Meißen und Bf. Julius Pflug von Naumburg-Zeitz an Ks. Karl V., Leipzig, 1. Januar 1549.

227 Vgl. MBW, Nr. 5423: Melanchthon an Mgf. Johann von Brandenburg-Küstrin, 24. Januar 1549. - Vgl. außerdem IssLeib, Das Interim in Sachsen (wie Anm. 6), S. 561, Anm. 57. 
Kurfürst Moritz interpretierte den Sachverhalt mehr zu seinen eigenen Gunsten. Mitte Januar übersandte er Johann von Küstrin die Artikel der Leipziger Landtagvorlage als das, was seine Untertanen beschlossen hätten, und gab freimütig zu, sich zuvor mit Joachim unterredet zu haben: Das ich beym Chufursten zu Brandenburg gewesen, ist war, es ist aber nichts gewisses beschlossen, dan was ich bey meinen undertanen kan erbalten. 228

Die Leipziger Landtagsvorlage erlangte aber gerade deswegen keine Gesetzeskraft, weil Moritz sie schlicht nicht publizieren ließ. Dagegen betraute er Georg von Anhalt gemäß seiner Ankündigung mit der Ausarbeitung einer neuen kursächsischen Kirchenordnung, ${ }^{229}$ der ,Georgsagende‘. Sie wurde ebenfalls abgelehnt und zwar am 10. April 1549 in Torgau und am 1. Mai 1549 in Pegau - diesmal von den katholischen Bischöfen und den Ständen. ${ }^{230}$

Joachim II., der am Zustandekommen der Leipziger Artikel maßgeblichen Anteil hatte, verlegte sich dagegen auf eine andere Strategie. Anstatt angesichts der aufgeheizten Stimmung in der Mark ${ }^{231}$ eine geschlossene Ablehnung der Stände auf einem Landtag zu riskieren, ${ }^{232}$ ließ er in den ersten Monaten des Jahres 1549 die Geistlichen, Lehrer und Bürgermeister des Landes in kleinen Gruppen zu sich kommen, um ihnen die Annahme des Augsburger Interims anzutragen. ${ }^{233}$ Ein Sekretär übergab den Pfarrern jeweils ein lateinisches Druckexemplar des Augsburger Interims, den Stadträten und Schulmeistern ein deutsches. Die Jüterboger Artikel nahmen eine untergeordnete, höchstens erläuternde Funktion ein.234 Joachim II. ließ die Jüterboger Beschlüsse darüber hinaus auch nicht im Druck ausgehen, obwohl er sich mit dem Leipziger Landtagsbeschluss sehr zufrieden

228 GStA PK, I. HA, Rep. 41 Beziehungen zu Kursachsen, Nr. 170: Schriftwechsel des Kurfürsten Moritz von Sachsen mit Markgraf Johann von Küstrin, fol. 732: Brief M.s an J., 16. Januar $1549=$ PKMS 4, Nr. 252, S. 295.

229 Siehe den Text abgedruckt bei Friedberg, Agenda (wie Anm. 130), S. 13-78.

$230 \mathrm{Vgl}$. dazu ausführlich ebd., S. 5-12; IssLeib, Das Interim in Sachsen (wie Anm. 6), S. 224229; Wartenberg, Philipp Melanchthon (wie Anm. 9), S. 76-78.

231 Vgl. Delius, Religionspolitik und kirchliche Ausgleichsbemühungen (wie Anm. 144), S. 35-38.

232 Berichte, ein solcher kurmärkischer Landtag oder Beratungen mit den brandenburgischen Landständen hätten stattgefunden, wie unter anderem bei IssLEIB, Das Interim in Sachsen (wie Anm. 6), S. 223, Anm. 57 kolportiert, sind nachweislich falsch. Vgl. dazu Müller, Zur Geschichte des Interims (wie Anm. 8), S. 146, 156, 171.

233 Ein Bericht über dieses eigentümliche Prozedere erschien anderthalb Jahrzehnte später im Druck: Andreas Hügel, Gründtlicher bericht/ was sich im jar des Herrn 1548. zu Berlin in der Marck des Jnterims halben zu getragen hab/ vnnd wie mans ins werck hat bringen wöllen (VD 16: H 5822), in: Matthias Flacius Illyricus/Victorinus Strigel (Hg.), DISPVTATIO DE ORIGINALI PECCATO ET LIBERO ARBITRIO, Basel 1563 (VD 16: F 1354), S. 548-568. Siehe überdies den Abdruck bei Müller, Zur Geschichte des Interims (wie Anm. 8), S. 155-170.

234 Vgl. Delius, Religionspolitik und kirchliche Ausgleichsbemühungen (wie Anm. 144), S. 42-44; Kawerau, Johann Agricolas Antheil (wie Anm. 37), S. 447-452; Müller, Zur Geschichte des Interims (wie Anm. 8), S. 147-171; Nischan, Die Interimskrise in Brandenburg (wie Anm. 196), S. 265-267. 
zeigte. ${ }^{235}$ Denn für den brandenburgischen Kurfürsten war bekanntlich das Augsburger Interim maßgeblich, weswegen den brandenburgischen Verhandlungen mit Kursachsen eine vor allem taktische Funktion unterstellt werden kann. Joachim II. und Agricola kamen ihrem kaiserlich-königlichen Auftrag nach, indem sie ihren albertinischen Kollegen weitere Konzessionen abrangen und ,auf Linie brachten', ohne von ihrer eigenen, klar interimistischen Position zu weichen.

Von den Wittenberger Theologen, die durch die märkischen Geistlichen des Öfteren um Rat angehalten wurden,236 wurde der Umstand, vom Hohenzoller und seinem Hofprediger mit den Verhandlungen zum Teil hinters Licht geführt worden zu sein, nicht recht realisiert. Melanchthon riet den Brandenburgern sogar weiterhin zu Konzessionsbereitschaft bezüglich der Zeremonien aus Rücksicht auf die Schwachen. ${ }^{237}$ Dem offenbar von Skrupeln geplagten Spandauer Pfarrer Christoph Lasius unterbreitete er obendrein den Vorschlag: Du kannst ja Deinen Diakonus die albernen Ceremonien ausfübren lassen. ${ }^{238}$ Der Eindruck erhärtet sich, dass rein politische Beweggründe für den philippistischen Adiaphorismus ursächlich waren.

In der Mark regte sich alsbald Widerstand. So wollte der Neustadt Brandenburger Pfarrer Andreas Hügel das Interim unter keinen Umständen annehmen und wurde von seinem Kurfürsten beurlaubt. Neben ihm verließen dann weitere renitente Prediger gar das Land. Es liegen aber Berichte vor, dass eine strikte Einhaltung der Interimsbestimmungen nicht überwacht wurde und man allgemein recht nachlässig verfuhr. Religiöser Zwang hätte Joachim II. vor seinen Ständen ohnehin nicht gut zu Gesicht gestanden, war er doch auf deren finanzielle Unterstützung angewiesen, - und wohl auch seiner Natur widersprochen.239 Dies mag aber nicht darüber hinwegtäuschen, dass Joachim II. prinzipiell am Augsburger Interim festhielt. ${ }^{240}$ Noch Anfang 1551 wusste Christoph von der Strassen an Michael, den Bischof von Merseburg, über den Herrn der Kurmark zu berichten, das Jnterim gefalle Jm ye lenger je besser, sei domit wol zufrieden und wolle dodurch wol selig werden, das auch zum hochsten vonnotten, domit eine ordnunge

235 Vgl. HStA Dresden, 10024 Geheimer Rat, Loc. 10298/1, fol. 281: Brief Joachims II. an Ludwig Fachs, Berlin, 8. Januar 1549.

236 Vgl. beispielsweise PKMS 4, Nr. 243, S. 285 f.: Propst Georg Buchholzer, Prediger Hieronymus Schwolle, Pfarrer Johannes Pommeranus (Baderesch) an Johannes Bugenhagen, Philipp Melanchthon und die anderen Theologen $\mathrm{zu}$ Wittenberg, Berlin, 7. Januar 1549 = CR 7, Nr. 4455, S. 292-296 = MBW, Nr. 5398.

237 Vgl. MBW, Nr. 5409: Gutachten Melanchthons [u. a. für die Kurmärker], Leipzig, 19. Januar $1549=$ CR 7, Nr. 4476, S. 321-326.

238 MBW, Nr. 5462: Melanchthon an Christoph Lasius, Wittenberg, 24. Februar $1549=$ CR 7, Nr. 4495, S. 341 f. - Vgl. die Übersetzung bei Nischan, Die Interimskrise in Brandenburg (wie Anm. 196), S. 267.

239 Vgl. Kawerau, Johann Agricolas Antheil (wie Anm. 37), S. 452-454; Müller, Zur Geschichte des Interims (wie Anm. 8), S. 154; Nischan, Die Interimskrise in Brandenburg (wie Anm. 196), S. 268.

240 Der Interpretation von Luttenberger, Glaubenseinheit und Reichsfriede (wie Anm. 7), S. 487 ist hier zu folgen. 
und vorgleichung in der religion furgenommenn, dan obne das moge je keiner mehr seiner underthanen mechtig sein. 241

Damit auch die Kursachsen den Kaiser milde stimmen und guten Willen demonstrieren könnten, beauftragte Kurfürst Moritz nach der Ablehnung der Georgsagende Philipp Melanchthon damit, einen Auszug aus dem Leipziger Interim, wie die Landtagsvorlage von ihren Gegnern polemisch genannt wurde, mit den wichtigsten Bestimmungen zu erstellen. Melanchthon, dem nicht ganz wohl dabei war, ließ sich dafür viel Zeit, sodass am 4. Juli der Text ${ }^{242}$ vorlag und erst Ende September/Anfang Oktober 1549 die gedruckten Exemplare ausgingen.243

Noch bevor dies geschehen konnte, war der nun in Magdeburg ansässige Matthias Flacius schneller gewesen, der sich in einer seiner vielen Flugschriften kritisch mit dem ihm zugespielten ,Kleinen Interim' auseinandersetzte. ${ }^{244}$ Besagter Gnesiolutheraner publizierte und kommentierte kritisch-höhnisch im Folgejahr auch das gesamte ,Leipziger Interim', ${ }^{\prime} 45$ das Moritz wohlweislich nie in den Druck gegeben hatte.

Das Hauptproblem sah Flacius gerade in den Adiaphora, denn die Katholiken wollten jene nicht das sein lassen, was sie nach philippistischer Vorstellung eben waren: Nebendinge, die die Erlangung des Seelenheils nicht berührten. ${ }^{246}$ Wäh-

241 HStA Dresden, 10024 Geheimer Rat, Loc. 7239/9: Brief von Christoph von der Strassen an Michael, Bischof zu Merseburg, Frankfurt/Oder, 19. Januar 1551, fol. $1^{\mathrm{v}}-2^{\mathrm{r}}$.

242 Vgl. PKMS 4, Nr. 397, S. 450-453: Außtzug aus dem Beschlus des Jüngst gehaltenen Landtags zu Leiptzigk in Weynachten, des Neunund viertzigsten Jars, 4. Juli $1549=$ CR 7, Nr. 4556, S. 426-428.

243 Vgl. Issleib, Das Interim in Sachsen (wie Anm. 6), S. 229 f.; Reichert, Amsdorff und das Interim (wie Anm. 9), S. 129 f.; Wartenberg, Philipp Melanchthon (wie Anm. 9), S. 78-80.

244 Vgl. Matthias Flacius Illyricus, Widder den ausszug des Leipsischen Jnterims oder das kleine Interim, Magdeburg 1549 (VD 16: F 1557) bzw. Ders, Wider den Auszug des Leipsischen Interims (1549), bearb. von Jan Martin Lies, in: Dingel, Der Adiaphoristische Streit (wie Anm. 7), S. 16-37.

245 Vgl. Matthias Flacius Illyricus/Nikolaus Gallus, Der Theologen bedencken/ odder (wie es durch die ihren inn offentlichem Drueck genennet wirdt) Beschluss des Landtages zu Leiptzig/ [...], Magdeburg 1550 (VD 16: S 926) = Dies., Der Theologen Bedenken oder Beschluss des Landtages zu Leipzig 1548 (,Leipziger Interim') nebst einschlägigen Dokumenten (1550), bearb. von Hans-Otto Schneider, in: Dingel, Der Adiaphoristische Streit (wie Anm. 7), S. 354-441.

246 Vgl. hier und im Folgenden z. B. Maren Ballerstedt/Peter Petsch/Matthias Puhle (Hg.), Magdeburger Drucke des 16. Jahrhunderts. Ein Bestandsverzeichnis (Magdeburger Schriften 2), Halle 2009; RoberT von Friedeburg, Magdeburger Argumentationen zum Recht auf Widerstand gegen die Durchsetzung des Interims (155051) und ihre Stellung in der Geschichte des Widerstandsrechts im Reich. 1523-1626, in: Schorn-Schütte, Das Interim 1548/50 (wie Anm. 2), S. 389-437; Kaufmann, Das Ende der Reformation (wie Anm. 4); Ders, Matthias Flacius Illyricus. Lutherischer Theologe und Magdeburger Publizist, in: Werner Freitag (Hg.), Mitteldeutsche Lebensbilder, Bd. 2: Menschen im Zeitalter der Reformation, Köln/Weimar/Wien 2004, S. 177-200; Moritz, Interim und Apokalypse (wie Anm. 4); Matthias Puhle (Hg.), ... gantz verheeret! Magdeburg und der Dreißigjährige Krieg. Beiträge zur Stadtgeschichte und Katalog zur Ausstellung des Kulturhistorischen Museums Magdeburg (Magdeburger Museumsschriften 6), Halle 21998 , S. 112-163. 
rend Melanchthon und seine Mitstreiter über diese Divergenz in der Interpretation freundlich hinwegsahen, legten die Gnesiolutheraner den Finger tief in jene Wunde hinein: Nibil est adiaphoron in statu confessionis et scandali, wurde zum Programm erhoben. Diesen Standpunkt vertraten sie mit Vehemenz, als sie vom geächteten Magdeburg aus, wohin sich die radikalen Lutheraner aufgrund der Durchsetzung des Interims beziehungsweise seiner kursächsischen Spielart geflüchtet hatten, einen Flugschriftenkrieg entfesselten, wie es ihn in seiner Intensität niemals zuvor und Jahrzehnte danach nicht mehr gegeben hatte. Für sie galt nur ein uneingeschränktes Bekennen ohne Subtilitäten oder Rücksichtnahmen. Selbst das Tragen eines Chorrocks war laut der Magdeburger schon eine Gefahr für die reine Religion, da dem Papsttum somit ein Anfang gemacht würde. Die Jenseitsausrichtung ihrer Lehre wird insofern offenbar, da man ihrer Vorstellung nach als wahrer Christ in der Welt leiden müsse, um sich nicht zu verleugnen. Politische Notwendigkeiten hatten sich für Flacius vollständig dem Gedanken des Evangeliums unterzuordnen, während Melanchthon aus Rücksicht auf die Schwachen bereit war, in religiösen Nebensächlichkeiten den anscheinenden politischen Notwendigkeiten Tribut zu zollen.

Ausgerechnet Moritz von Sachsen wurde vom Kaiser für die Belagerung Magdeburgs (1550/51) abgestellt. Nachdem die Stadt kapituliert hatte, deren Theologen zuvor eine theologisch unterlegte Widerstandslehre, das ,Magdeburger Bekenntnis‘, zur Legitimation der eigenen Unbotmäßigkeit erstellt hatten, zog Moritz mit seinem großen Heer im Fürstenkrieg (1552) gegen den Kaiser selbst. Sein Ziel war unter anderem, die Rücknahme des Interims zu erreichen, das für so viel Hader unter den Lutheranern Anlass gegeben hatte. Der Passauer Vertrag von 1552 und der Augsburger Religionsfrieden von 1555 legten mit der Festschreibung des Landfriedens für Katholiken und Lutheraner das Augsburger Interim und seine kursächsische Spielart schließlich ad acta.

\section{Resümee}

Die für das Konfessionelle Zeitalter so charakteristische Verbindung von Politik und Bekenntnis hatte die Erstellung der Leipziger Artikel nicht nur maßgeblich beeinflusst, sondern überhaupt erst verursacht. Indem Karl V. als weltliches Oberhaupt des Reiches das Augsburger Interim in Auftrag gab, trachtete er - gemäß seinem Selbstverständnis als Schutzherr der katholischen Kirche - nach einem Eingriff in die religiösen Verhältnisse der einzelnen Territorien, die jeweils aber ihre ganz spezifische Religionspolitik verfolgten. Ob sich der frühneuzeitliche Staatsbildungsprozess auf territorialer oder Reichsebene durchsetzen würde, war keineswegs vorgezeichnet oder absehbar gewesen. Während Karl V. die religiöse Einheit im Reich als unabdingbare Voraussetzung für den Friedenserhalt ansah, wäre für Moritz jede grundlegende Abweichung vom Luthertum mit unabsehbaren innenpolitischen Folgen in Kursachsen verbunden gewesen. 
Zusätzlich zu ihrem gegenseitigen Abhängigkeitsverhältnis wegen ihres Zusammenwirkens im Schmalkaldischen Krieg waren Karl V. und Moritz in der Religionssache auf ihre Stände angewiesen. Ein autokratisches Agieren wäre aufgrund der verfassungsmäßigen Gegebenheiten schlicht nicht durchsetzbar gewesen. Für das Reich schlägt sich dieser Umstand darin nieder, dass der Kaiser den katholischen Ständen nachgeben musste, als sie den Geltungsbereich des Interims allein auf die Protestanten beschränkt wissen wollten und jede Unterwerfung unter ein Reichsreligionsgesetz kategorisch ablehnten. Kurfürst Moritz dagegen verwies sogar offensiv im Zuge der Verhandlungen über die Annahme des Augsburger Interims darauf, dass er an das Wohlwollen und die Zustimmung seiner Stände gebunden sei. Und dessen konnte sich der Sachse nur sicher sein, weil er mit Philipp Melanchthon und seinen Kollegen die anerkannten theologischen Autoritäten des Luthertums an seiner Seite zu sammeln vermochte.

Als Moritz seinen Theologen den Auftrag gab, das Augsburger Interim zu prüfen und sodann einen eigenen Vergleichstext zu erstellen, blieb das durchaus keine rein innersächsische Angelegenheit. Denn Kurfürst Joachim II. von Brandenburg wirkte mit seinem Hofprediger Johann Agricola auf Geheiß von König Ferdinand und Kaiser Karl V. auf den Fortgang der Verhandlungen ein. Agricola hatte sich wie der katholische Bischof von Naumburg Julius Pflug, der streckenweise ebenfalls zu den sächsischen Beratungen hinzugezogen wurde, bereits an der Augsburger Interimskommission beteiligt. So nimmt es nicht wunder, dass sie bestrebt waren, die entstehenden Leipziger Artikel so nah wie möglich am Augsburger Interim auszurichten.

In mühevoller Kleinarbeit entstand auf mehreren Theologenversammlungen der kursächsische Sondervergleichstext, wobei Kurfürst Moritz durch die Auswahl von verständigungsbereiten Theologen und die Involvierung weltlicher Räte auf dessen Grundausrichtung Einfluss zu nehmen wusste. Letztere rangen den Theologen immer mehr Kompromissbewilligungen ab, verfolgten also eine politische Einflussnahme auf theologische Entscheidungen. Dem politischen Druck konnten und wollten sich Philipp Melanchthon und die übrigen Theologen angesichts eines drohenden Krieges kaum entziehen. Um den vermeintlichen politischen Notwendigkeiten nachzukommen, unter Wahrung der reinen lutherischen Lehre, griffen sie auf das Konzept der Adiaphora zurück. Darunter sollten jene liturgischen Handlungen und Requisiten in den Kirchen fallen, die auf die Erlangung des Seelenheils keinen Einfluss hätten, wie etwa Gesänge, Kleider oder Bilder in Kirchen. Durch die partielle Wiederherstellung der liturgischen Einheit mit der Altkirche hofften die kursächsischen Theologen, die Kernstücke evangelischen Glaubens bewahren zu können. Niemand sollte wegen solcher Nebensächlichkeiten leiden müssen. Die Mitteldinge wurden also aus politischem Kalkül und nicht aufgrund religiöser Überzeugung in die Überlegungen einbezogen. Darüber hinaus verzichteten die an der Ausarbeitung der kursächsischen Kompromissformel beteiligten Theologen auf jede öffentliche Polemik gegen den Kaiser und sein Religionsgesetz. 
Als im Winter 1548 in Leipzig die Landtagsvorlage als ,Der Theologen Bedenken' den Ständen zur Annahme angetragen wurde, wurde ihnen die massive Einflussnahme der weltlichen Räte des Kurfürsten Moritz auf die Ausgestaltung der Artikel verschwiegen. Einerseits offenbarten die Ständevertreter ihr Verständnis vom Zusammenhang politisch-administrativer und religiöser Vorgänge, indem sie die bischöfliche Jurisdiktion ablehnten. Andererseits beugten sie sich dem scheinbar Unvermeidbaren, als sie die restlichen Artikel billigten. Da die beiden anwesenden katholischen Bischöfe, Julius Pflug und Johann VIII. von Maltitz, ihr Einverständnis zu einer so weitreichenden Modifizierung der kaiserlichen Interimsartikel nicht geben wollten, wurde die sächsische Fassung zunächst nicht publik gemacht und dadurch auch nicht in Kraft gesetzt.

Die Einheit des Luthertums war dennoch nachhaltig geschädigt. Von Magdeburg aus, das sich als von seiner erzstiftischen Landesherrschaft gelöst betrachtete, polemisierten die in jene Stadt geflohenen Gnesiolutheraner gegen jede Form des Kompromisses - weil ihnen das in der geächteten Elbmetropole eben gestattet wurde. Das adiaphoristische Konzept sei aus dem Grund nicht auf die gegenwärtigen Zeiten anwendbar, weil die Einführung von Mitteldingen in diesem Zusammenhang ein Nachgeben gegen die Feinde Gottes sei. Mithilfe religiöser Deutungsmuster versuchten sie zudem, den Widerstand gegen die bisher rechtmäßigen, weltlichen Obrigkeiten zu legitimieren, um die eigene Unabhängigkeit $\mathrm{zu}$ erreichen.

Die theologische Verwirrung unter den Protestanten mit der Aufspaltung in viele konkurrierende Lehrschulen bis zur Unterzeichnung der Konkordienformel von 1577 ist nur dann verständlich, wenn man sich der Umstände der Entstehung, der Bestimmungen und der Durchsetzung der Leipziger Artikel infolge der Verabschiedung des Augsburger Interims bewusst ist. Interimisten, Adiaphoristen und Gnesiolutheraner sollten nicht die einzigen protestantischen Gruppierungen bleiben, die die alleinige Wahrheit für sich mit großem Bekennereifer in Anspruch nahmen.

Die Religion stellte zwar mitunter die wichtigste Triebfeder politischen Handelns dar, aber das Vorgehen in Religionsfragen knüpfte sich stets an die machtpolitischen Möglichkeiten der jeweils Agierenden. So war gerade in Kursachsen die Religion in ,Geiselhaft ${ }^{\prime}$ für den Friedenserhalt genommen worden, und im Ergebnis hatte der Kaiser auch sein Ziel nicht erreichen können, seine universelle Herrschaftsidee auf eine einheitliche Reichskirche zu stützen. 